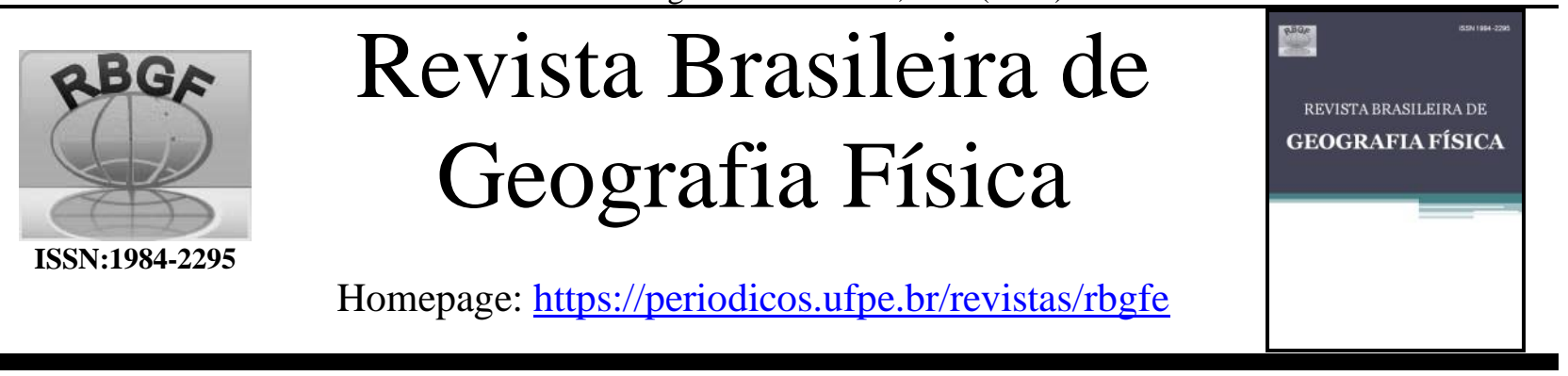

\title{
Variação Microclimática em Sítios Urbanos com Diferentes Níveis de Cobertura Vegetal Como Subsídio à Formação de Ilha de Calor
}

\begin{abstract}
Pedro Hugo Oliveira Moreira ${ }^{1}$, Alan Cavalcanti da Cunha² ${ }^{2}$ João de Athaydes Silva Júnior ${ }^{3}$, Antônio Carlos Lola da Costa ${ }^{4}$
${ }^{1}$ Mestre em Ciências Ambientais pela Universidade Federal do Amapá (UNIFAP). Pedrohugo.moreira@ gmail.com. ${ }^{2}$ Prof. ${ }^{\circ}$ Dr. Associado III do Curso de Engenharia Civil - da Universidade Federal do Amapá (UNIFAP). Programa de Pós-graduação PPGCA/PPGBio/BIONORTE/UNIFAP. Rod. Juscelino Kubitschek. de Oliveira, km 02 - Campus Marco Zero do Equador - AP, CEP 68.903-419. alancunha@ unifap.br. ${ }^{3 P r o f}{ }^{\circ}$ Dr. Adjunto da Faculdade de Meteorologia da Universidade Federal do Pará (UFPA). Programa de Pós-Graduação em Gestão de Riscos e Desastres Naturais na Amazônia. PPGGRD-UFPA Rua Augusto Correa - Campus Universitário Guamá. CEP: 66075-110, Belém-PA. athaydes @ ufpa.br. ${ }^{4}$ Prof. Dr. Titular aposentado da Faculdade de Meteorologia da Universidade Federal do Pará (UFPA). Rua Augusto Correa - Campus Universitário Guamá. CEP: 66075110, Belém-PA. lola@ufpa.br.
\end{abstract}

Artigo recebido em 22/10/2020 e aceito em 11/12/2020

\section{R E S U M O}

O objetivo da investigação é analisar variações espaciais e sazonais de elementos meteorológicos que evidenciam a formação e ocorrência do fenômeno da Ilha de Calor Urbana (ICU) na cidade de Macapá. A metodologia de estudo avaliou a evolução histórica da cobertura de vegetação e da malha urbana utilizando-se técnicas de geoprocessamento e de classificação supervisionada de Máxima Verossimilhança (MAXVER). Com este objetivo foram analisadas séries de dados contínuos coletados durante dez dias consecutivos nos períodos chuvoso (Abril/2018), Seco (Novembro/2018) e Transição (Junho/2019). Os elementos meteorológicos quantificados foram a umidade relativa do ar (UR) e a temperatura média do ar (T). Cinco estações semi-automáticas foram estrategicamente distribuídas ao longo de dois eixos de máximo prolongamento da zona urbana de Macapá, nos sentidos Nordeste-Sudoeste e Oeste-Leste. Os resultados indicaram significativa variação sazonal da Temperatura e da Umidade Relativa $(\mathrm{p}<0,05)$. Espacialmente, os resultados também foram significativos $(\mathrm{p}<0,05)$, sugerindo influência espaço-sazonal dos padrões de variabilidade de T e UR sobre ICU correlacionados com as taxas de uso e ocupação do solo. Assim, ICU mostrou-se significativamente dependente tanto do índice de vegetação $\left(R^{2}=0,47, p<0,05\right)$ quanto do índice de urbanização $\left(R^{2}=0,62, p<0,05\right)$. Conclui-se que a sazonalidade diária observada sugere existência do fenômeno da ilha de calor urbana, especialmente nas zonas central e sul da cidade, cujos índices inclusive têm sido confirmados por estudos similares. Os dados de sazonalidade dos elementos meteorológicos analisados, sua relação com o uso do solo, podem trazer elementos importantes para o debate sobre a formação da ICU nas cidades amazônicas.

Palavras-Chave: Elemento meteorológico, vegetação, urbanização, ilha de calor urbana, Macapá.

\section{Microclimatic Variation in Urban Sites with Different Levels of Vegetable Cover as a Subsidy to the Formation of Heat Island}

\begin{abstract}
A B S T R A C T
The objective of the investigation is to analyze spatial and seasonal variations of meteorological elements that evidence the formation and occurrence of the phenomenon of the Urban Heat Island (UHI) in the city of Macapá. The study methodology comprised the historical evolution of vegetation cover and urban space using geoprocessing techniques and supervised classification of Maximum Likelihood (MAXVER). With this objective, continuous data series collected during ten consecutive days in the rainy (April/2018), Dry (November/2018) and Intermediate (June/2019) periods were analyzed. The meteorological elements quantified were relative humidity (RH) and average air temperature (T). Five semi-automatic gauges were strategically distributed along two axes of maximum extension of the urban area of Macapá, in the Northeast-Southwest and West-East directions. The results indicated significant seasonal variation of Temperature and Relative Humidity $(\mathrm{p}<0.05)$. Spatially, the results were also significant $(\mathrm{p}<0.05)$, suggesting influence of $\mathrm{T}$ and $\mathrm{RH}$ variability patterns on UHI correlated with land use and occupation rates on. Thus, ICU was significantly dependent on
\end{abstract}

Moreira, P. H. O., Cunha, A. C., Silva Júnior, J. A., Costa, A. C. L. 
Revista Brasileira de Geografia Física v.13, n.07 (2020) 3254-3274.

both the vegetation index $\left(\mathrm{R}^{2}=0.47, \mathrm{p}<0.05\right)$ and the urbanization index $\left(\mathrm{R}^{2}=0.62, \mathrm{p}<0.05\right)$. We concluded that the daily seasonality observed suggests the existence of the phenomenon of the urban heat island, especially in the central and southern zones of the city, whose indices have even been confirmed by similar studies. The seasonality data of the meteorological elements analyzed, their relationship with land use, can bring important elements to the debate on the formation of ICU in Amazonian cities.

Keywords: Meteorological element, vegetation, urbanization, urban heat island, Macapá.

\section{Introdução}

A ilha de calor urbana (ICU) é definida como o significativo aumento da temperatura da superfície e do ar sobre uma área urbana em relação as áreas rurais ou suburbanas vizinhas (Arya, 2001).

O fenômeno ICU apresenta variações de efeitos de aquecimento local ou microclimáticos, com intensidades maiores durante a estação seca e menores durante a estação úmida. Isto ocorre em virtude da energia recebida ser modulada pela disponibilidade de água (umidade relativa) e uma maior influência promovida pela vegetação sobre o microclima úmido (Roth, 2007).

Historicamente este fenômeno é resultante de um efeito colateral de processos de expansão urbana, o qual está associado com a retenção de calor, alteração do albedo de superfície e variabilidade na dispersão de poluentes e aerossóis. $\mathrm{O}$ fenômeno da ICU foi observado pela primeira vez na literatura por Luke Howard em 1833, em Londres, e posteriormente confirmada por Émillien Renou, em Paris (Leal Filho et al., 2017).

A energia incidente na superfície terrestre (natural e antropizada) é devolvida para a atmosfera na forma de fluxo de calor sensível (aquecimento) e latente (evapotranspiração). Quando a cobertura do solo é virtualmente alterada, a compartimentação urbana provoca diferenciações microclimáticas que são importantes para uma série de estudos, com destaque para a avaliação do nível de conforto térmico das cidades (Costa et al., 2013).

Portanto, a cidade deve ser vista como um sistema aberto e adaptativo de energia em trânsito, sofrendo interferências das variáveis atmosféricas como o vento, relevo, brisas fluviais, marítimas (Sanches et al., 2018). Deste modo, os fenômenos climáticos são de fato resultantes deste processo de troca de energia entre o ar atmosférico e o solo, haja vista que as superfícies refletem energia de diferentes formas e intensidades (Nóbrega et al., 2016).

As causas deste processo são a modificação da superfície natural por edificações e pavimentação, que causam a impermeabilização da superfície do solo. Estes materiais artificiais aumentam o nível de escoamento superficial da água, reduz a capacidade de infiltração do solo, elevam a condutividade térmica e a capacidade da área afetada de armazenar calor, quando comparadas com o ambiente rural (Corrêa et al., 2016). Materiais artificiais, utilizados nas zonas urbanas, tendem a ser mais escuros do que os das áreas rurais. Portanto, absorvem e armazenam mais energia e, devido a maior impermeabilidade do solo, a água não consegue infiltrar e dissipar a energia armazenada por meio do processo de evaporação ou de evapotranspiração, quando há ainda alguma vegetação (Santiago; Gomes, 2016).

Outros fatores que contribuem com a ICU são as aglomerações populacionais e o trânsito local, ou em determinadas regiões concentradas nas cidades. Ambas modificam a temperatura local, intensificadas pelo efeito de calor e pela posição e deslocamento das fontes térmicas, consequentemente contribuindo com o fenômeno da ICU (Zhu et al., 2017).

A súbita diferença ou desequilíbrio de calor entre regiões geográficas próximas é o que favorece a formação do fenômeno da ICU. E esta ocorre dentro da conhecida Camada Limite Urbana - CLU), em uma porção atmosférica de até $1 \mathrm{~km}$ de altura. Desta forma, as áreas urbanas são mais vulneráveis ao aquecimento térmico do que as áreas rurais (Zhang et al., 2019).

A intensidade da ICU amplia-se com o tamanho da cidade e a escala regional de convecção do ar. Além disso, depende da forma geométrica da área alterada, se mais ou menos compacta, em comparação com tecidos urbanos mais dispersos (Zhou et al., 2017).

Dentre as consequências do calor intenso nas cidades estão a redução do conforto térmico, alteração da capacidade de dispersão de poluentes no ar, a influência negativa no deslocamento diário dos moradores, a redução da produtividade no trabalho e a piora do desempenho das atividades humanas ao ar livre. Desta forma, uma estimativa mais precisa sobre os locais em que o fenômeno da ICU ocorre, melhoram a capacidade na execução de políticas vinculadas ao planejamento urbano das cidades, induzindo ao aumento da qualidade de vida e segurança de seus habitantes (Zhang et al., 2019).

Entretanto, apesar da importância do fenômeno de ICU para o planejamento do uso e ocupação do solo urbano, há poucos estudos desta 
Revista Brasileira de Geografia Física v.13, n.07 (2020) 3254-3274.

natureza em cidades brasileiras de baixas latitudes, principalmente na Amazônia (Silva Junior, 2012a).

O crescimento urbano brasileiro, ocorrido principalmente entre as décadas de 1940 e 1990, provocou a intensificação do uso e ocupação do solo e que se concentraram principalmente em áreas urbanas. Assim, o aumento da população urbana, que a partir da década de 1970 constituía mais da metade da população brasileira $(55,92 \%)$, provocou um aumento do território urbano, favorecendo a ocorrência do fenômeno da ilha de calor nesses locais (Porangaba et al., 2017).

As cidades amazônicas, que cresceram especialmente a partir da década de 1960, genuinamente localizadas em ambientes tropicais, embora façam parte de uma mesma macrorregião, possuem nuances e características físicas e ambientais distintas. Por exemplo, cidades mais próximas de grandes corpos d'água tendem a apresentar menores evidências e impactos sobre os índices de calor (formação de ilhas de calor), independentemente de suas dimensões, mas relacionadas e favorecidas pelos efeitos de brisas predominantes (Barbosa et al., 2015).

As grandes e médias cidades da região, como Santarém-PA, Macapá-AP, Manaus-AM e Belém-PA vêm aparentemente sofrendo mais com o fenômeno da ilha de calor. Nestes casos, quando as temperaturas tendem a ser mais elevadas nas zonas mais urbanizadas, estas geralmente ocorrem nos bairros mais centrais e urbanizados ou verticalizados. Porque estas áreas tendem a apresentar menores níveis de albedo quando comparadas com as áreas vegetadas, o que implica em uma tendência de maior aquecimento nessas zonas específicas (Silva Junior et al., 2013a).

Como a urbanização também tende a gerar impactos térmicos sobre o microclima local e, consequentemente, na qualidade de vida da população, estes impactos podem e são frequentemente aferidos por índices de conforto térmico e eficiência energética ou similares (Terra De Oliveira et al., 2017). Amorim e Dubreuil (2017) afirmam que a maior intensidade da ICU ocorre à noite e é mais intensa em ambientes tropicais em relação aos temperados.

Por exemplo, a cidade de Macapá, objeto principal de análise do presente estudo, está localizada na região Sudeste do Estado do Amapá, em zona costeiro-estuarina ( $0^{\circ} 2$ ' 4" $\mathrm{N}$ e $51^{\circ} 3^{\prime} 60^{\prime}$ ' $\mathrm{W})$, com área de $6.503,458 \mathrm{~km}^{2}$, índice de arborização de vias públicas de $66 \%$, inserida em uma bacia hidrográfica composta ou próximas de grandes corpos d'água que interligam essas grandes massas às áreas, como as áreas de ressacas (sazonalmente inundadas) (Torres e Robinni, 2018).

Alguns estudos têm apresentado uma série de indicadores de temperatura e precipitação que sugerem elevada probabilidade do aumento da frequência do fenômeno da ICU na capital amapaense (Santos et al., 2012). Isso é consequência do sensível adensamento populacional urbano (população estimada em 2018 era de 493.634 habitantes). Este crescimento populacional, portanto, parece ser expressivo quando comparado com a população da década de 1970, de 116.480 habitantes.

Segundo Silva (2016), transformações políticas e econômicas locais, como a implantação da Área de Livre Comércio de Macapá e Santana em 1991 foram um dos principais fatores que contribuíram com estas elevadas taxas de crescimento populacional e urbano.

A autora analisou a variação geográfica de alguns dos impactos do crescimento urbano da cidade de Macapá a partir da modificação do seu microclima, com foco no fenômeno da ICU e dos índices de conforto térmico. Avaliou que o crescimento urbano de Macapá ocorreu primeiramente em direção ao norte (bairros Novo Horizonte, Jardim I e II, Renascer, Brasil Novo), posteriormente a regiões oeste (regiões dos bairros Marabaixo, Goiabal e Cabralzinho) (Figura 01). Atualmente este crescimento ocorre em direção a região sul (Universidade, Zerão, condomínios residenciais no entorno da Rodovia JK, Fazendinha). Porém, estas alterações também ocorrem em algumas áreas de crescimento dispersas e isoladas. $\mathrm{O}$ destaque, nesta nova fase de expansão atual da malha urbana ocorre na zona sul, onde se localiza o Distrito da Fazendinha, localizado entre o centro da cidade de Macapá e o centro da Cidade de Santana, segundo maior município do Estado (Silva, 2016).

Na presente pesquisa, a hipótese é de que há indícios significativos da existência da ICU em Macapá, o qual pode ser identificado pela distribuição geográfica da cobertura vegetal, utilizada como fator independente relevante na redução dos processos de aquecimento térmico do solo para a atmosfera em Macapá. Uma segunda hipótese é que este potencial padrão geográfico de distribuição térmica varia sazonalmente (temperatura e umidade relativa do ar), sendo mais evidentes em sítios mais urbanizados e vice-versa, cujas superfícies também tendem a ser mais artificialmente alteradas. Estes indícios sugerem uma manutenção da tendência ao aquecimento no interior destas manchas urbanas de Macapá, já identificadas em estudos anteriores, porém 
Revista Brasileira de Geografia Física v.13, n.07 (2020) 3254-3274.

limitados à apenas uma única estação (Santos et al., 2012).

O presente estudo, aprofunda esta visão, acrescentando a variação espacial (geográfica), preenchendo uma lacuna de conhecimento inédita de estudos desta natureza no Estado do Amapá, associando esta característica espacial com a sazonalidade (com a inserção do período de transição na tentativa de entender a variabilidade da T e UR) e a cobertura de uso do solo.

Assim, a presente pesquisa, que faz parte de um conjunto de pesquisas de análise climática e de conforto térmico, pretende estimular o debate e a produção de trabalhos sobre o clima urbano nas cidades amazônicas brasileiras, que segundo Roth (2007) são ainda carentes neste sentido.

Com base nestas referências, deduz-se que a vegetação e a expansão urbana são fatores que podem estar influenciando os efeitos da ICU. A presente pesquisa objetiva, portanto, analisar a existência de potenciais correlações entre a temperatura do ar e a umidade relativa do ar. Os parâmetros geográficos mensuráveis serão quantificados por SIG, especialmente os parâmetros relacionados com o uso e a ocupação do solo. Para cumprir com este objetivo geral, foi realizada uma série de três campanhas sazonais de coleta de dados em campo utilizando sensores térmicos. Desta forma, foram elaboradas análises microclimáticas de curta duração em pelo menos cinco localidades (bairros diferentes) a fim de avaliar a influência de gradientes espacial a serem testados estatisticamente.

\section{Material e métodos}

Área de Estudo e Coleta de dados

A área geográfica focal de estudo é a zona urbana de Macapá representada pela Figura 01. Esta área está subdivida pelos respectivos bairros, sobre os quais foram distribuídas cinco estações semi-automáticas para o monitoramento dos elementos meteorológicos (UNIFAP, Museu Sacaca, Curiaú, Marabaixo e Fazendinha).

Trabalho de campo

A etapa metodológica se iniciou com o trabalho de campo de reconhecimento dos locais de instalação das cinco estações meteorológicas semiautomáticas. As estações de coleta foram selecionadas e geograficamente dispostas no eixo Sudoeste-Nordeste e Oeste-Leste (Figura 01 e Tabela 01), tendo como critérios abranger todas as características físicas (muito ou pouco arborizado, muito ou pouco edificado, dentre outras), de diferentes zonas urbanas da cidade (Norte, Sul, Oeste, Centro). Desta forma é possível capturar a influência das características de ocupação do solo no fenômeno da ICU. Além destes critérios, são utilizados os dois elementos meteorológicos ( $\mathrm{T}$ e UR) e suas correlações com áreas vegetadas e urbanizadas para avaliar o papel da sazonalidade e espacialidade climática sobre ICU. Portanto, a representatividade estatística entre uso do solo e temperatura do ar e umidade relativa do ar, além da segurança dos equipamentos e a facilidade logística de operação foram critérios que definiram a escolha dos locais. 


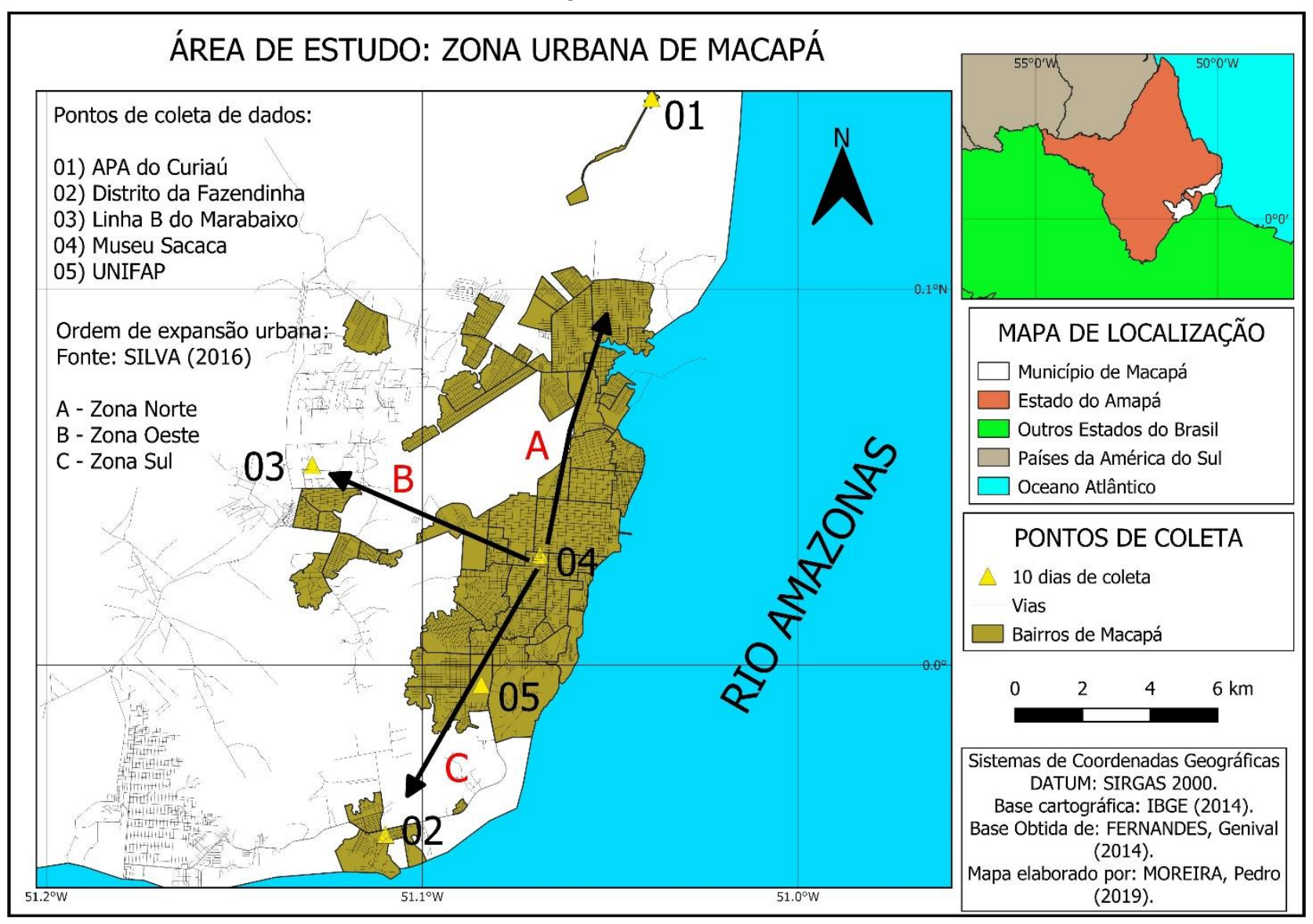

Figura 01: Pontos de coleta das estações na área de estudo

Tabela 01: Caracterização física e microclimática das áreas de estudo.

\begin{tabular}{|c|c|c|c|c|}
\hline $\begin{array}{c}\text { Sítio } \\
\text { Amostral }\end{array}$ & Local & $\begin{array}{l}\text { Eixo da } \\
\text { Cidade }\end{array}$ & Lat/Long & $\begin{array}{l}\text { Caracterização da área/Critério da escolha dos } \\
\text { pontos }\end{array}$ \\
\hline 01 & $\begin{array}{l}\text { APA do } \\
\text { Curiaú }\end{array}$ & $\begin{array}{l}\text { Zona } \\
\text { Norte }\end{array}$ & $\begin{array}{l}0^{\circ} 99^{\prime} 3,00 ” \mathrm{~N} \\
51^{\circ} 2,20,37 ” \mathrm{O}\end{array}$ & $\begin{array}{l}\text { Figura 03A - Área periurbana do município, } \\
\text { muito arborizado e pouco edificado com baixa } \\
\text { circulação de pessoas e veículos. }\end{array}$ \\
\hline 02 & $\begin{array}{l}\text { Distrito da } \\
\text { Fazendinha }\end{array}$ & $\begin{array}{l}\text { Extremo } \\
\text { Sul - } \\
\text { Periferia }\end{array}$ & $\begin{array}{l}0^{\circ} 2^{\prime} 42,32 \% \mathrm{~S} \\
51^{\circ} 6{ }^{\prime} 35,49 " \mathrm{O}\end{array}$ & $\begin{array}{l}\text { Figura 03B - Localizado na área urbana entre a } \\
\text { região central dos municípios de Macapá e } \\
\text { Santana. Instalado na Estação Climatológica da } \\
\text { Fazendinha (INMET). É uma área } \\
\text { significativamente urbanizado e pouco } \\
\text { arborizado, com baixa circulação de veículos. }\end{array}$ \\
\hline 03 & $\begin{array}{l}\text { Linha B do } \\
\text { Bairro } \\
\text { Marabaixo }\end{array}$ & $\begin{array}{l}\text { Zona } \\
\text { Oeste }\end{array}$ & $\begin{array}{l}0^{\circ} 3{ }^{\prime} 11,74 ” \mathrm{~N} \\
51^{\circ} 77^{\prime} 45,43 ” \mathrm{O}\end{array}$ & $\begin{array}{l}\text { Figura } 03 \mathrm{C} \text { - Localizada em zona rural, o ponto } \\
\text { mais ocidental neste trabalho, é relativamente } \\
\text { arborizado e pouco urbanizado, com grande } \\
\text { área de solo exposto, sendo parcialmente } \\
\text { coberto por grama e árvores frutíferas de } \\
\text { pequeno porte, por toda a extensão do terreno. }\end{array}$ \\
\hline 04 & $\begin{array}{l}\text { Museu } \\
\text { Sacaca }\end{array}$ & $\begin{array}{l}\text { Centro- } \\
\text { Sul }\end{array}$ & $\begin{array}{l}0^{\circ} 1^{\prime} 45,23 ” \mathrm{~N} \\
51^{\circ} 4,7,00^{\prime \prime} \mathrm{O}\end{array}$ & $\begin{array}{l}\text { Figura 03D - Localizada na parte central de } \\
\text { Macapá, próxima a um Canal de drenagem, é } \\
\text { uma área extremamente arborizada, porém } \\
\text { muito urbanizada no seu entorno. }\end{array}$ \\
\hline 05 & $\begin{array}{l}\text { Universidade } \\
\text { Federal do } \\
\text { Amapá } \\
\text { (UNIFAP) }\end{array}$ & Zona Sul & $\begin{array}{l}0^{\circ} 0^{\prime} 18,60^{\prime \prime} \mathrm{S} \\
51^{\circ} 5,3,46^{\prime \prime} \mathrm{O}\end{array}$ & $\begin{array}{l}\text { Figura 03E - Localizado próximo de área } \\
\text { florestada, em campo aberto. No seu entorno há } \\
\text { presença de superfície cimentícia (passarelas } \\
\text { dos blocos) e asfáltica (vias da universidade). }\end{array}$ \\
\hline
\end{tabular}


Revista Brasileira de Geografia Física v.13, n.07 (2020) 3254-3274.

Desta forma, foram realizadas três campanhas de campo: a primeira no período úmido (Abril/2018), a segunda no período seco (Novembro/2018) e a terceira no período denominado intermediário (Junho/2019). A principal justificativa para a campanha intermediária (período de transição) é contribuir ineditamente com avaliações comportamentais do padrão dos elementos meteorológicos também entre os extremos de período chuvoso e seco, comumente utilizado na literatura (Leal Filho et al., 2017). Espera-se com esta contribuição adicional melhor compreender como ocorre o processo de transição entre os períodos chuvoso e seco e qual o seu papel no processo do fenômeno ICU.

No período seco, nos meses de setembro a novembro as temperaturas médias do ar variam entre 27,50 e $28,50^{\circ} \mathrm{C}$. No período chuvoso, de março a maio, a temperatura média do ar média varia entre 26,20 e $26,70^{\circ} \mathrm{C}$. No período intermediário desta pesquisa, em junho, ocorrem temperaturas médias do ar de aproximadamente $26,70^{\circ} \mathrm{C}$ (INMET, 2018). Além da temperatura do ar, a precipitação interferiu na escolha dos meses de coleta dos dados. A campanha de período seco ocorreu obrigatoriamente entre os meses de setembro e novembro, quando os níveis de precipitação oscilam na média entre 40 e $60 \mathrm{~mm}$ mensais. Por sua vez, a coleta no período chuvoso, ocorreu obrigatoriamente entre os meses de março e maio, com as precipitações atingindo cerca de 330 a $410 \mathrm{~mm}$. O período intermediário ocorreu no mês de junho, com precipitação média de $220 \mathrm{~mm}$ (INMET, 2018).

Para a coleta de dados, foram usados Microloggers ou Dataloggers, modelo Hobo ${ }^{\circledR}$ Data Logger U10-003 e o sensor UX100-023 (mesma confiabilidade do sensor U10-003) na UNIFAP, aparelhos que fazem a medição da temperatura e da umidade relativa do ar, instalados dentro de abrigos meteorológicos localizados 1,5 metros do solo, com ventilação natural por todos os lados $\mathrm{e}$ programados para coletar os dados a cada quinze minutos, conforme recomendações da Organização Meteorológica Internacional (WMO, 2012). O mesmo sensor foi utilizado por Silveira e Carvalho (2016), com amplitude térmica confiável para análise de $20^{\circ} \mathrm{C}$ até $70^{\circ} \mathrm{C}$. Neste experimento será utilizado o Abrigo Meteorológico Alternativo (AMA), que substituiu o abrigo meteorológico padrão, modelo da empresa Campbell Sci®, o 41003-510 Plate Gill Radiation Shield e possui a mesma confiabilidade em relação a este, não permitindo a entrada da chuva e da radiação solar direta em nenhum momento do dia, devido a superposição entre os anéis (inferior e superior) que bloqueia a dos elementos citados. Além disso, é uma opção mais barata e acessível em relação ao abrigo meteorológico padrão. O AMA foi pintado a tinta óleo na cor branca, que favorece ao albedo e a reflexão da radiação solar (Silva, 2016).

A metodologia utilizada no aspecto da sazonalidade da temperatura do ar nos locais arborizados e pouco arborizados sofreu algumas adaptações, especialmente com relação aos locais com alto nível de urbanização e aqueles com pouco nível de urbanização proposta por Silva Junior (2012). Esta metodologia consiste na classificação dos tipos de cobertura do solo utilizando uma imagem de satélite de alta resolução da cidade de Macapá, por meio do aplicativo Google Earth®. Após a imagem passar por correções iniciais (georreferenciamento) foi extraída do entorno da área de coleta de dados com raio aproximado de $100 \mathrm{~m}$.

\section{Análises MAXVER - Uso e Ocupação da Terra}

Além das campanhas de campo, foram aplicadas técnicas de classificação supervisionada de Máxima Verossimilhança (MAXVER) sobre o uso e ocupação do solo, por meio do software $P C I$ geomatics Free Trial.

A Figura 02 mostra o processo de crescimento da mancha urbana no tempo. No início da década de 1990 esta mancha estava concentrada na parte central da cidade de Macapá, próxima ao Rio Amazonas. Em 2000 já se verifica um crescimento da mancha urbana nas direções norte, oeste e sul em relação ao centro, identificada pelos pixels de cor vermelha. E, por fim, no ano de 2017, ocorreu um adensamento em simultaneidade com a expansão genérica da mancha urbana de Macapá. 


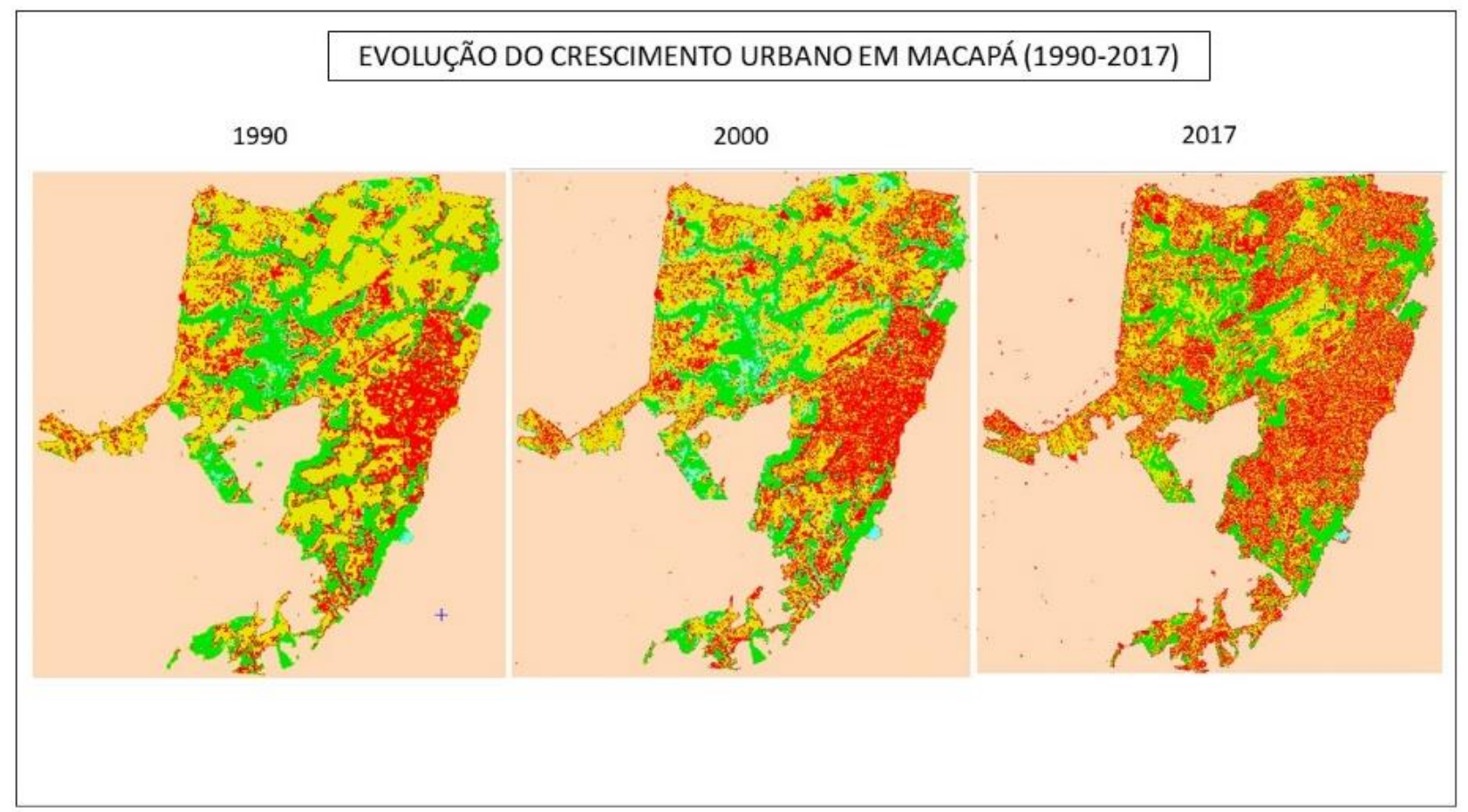

Figura 02: Mapa de evolução do crescimento da malha urbana da cidade de Macapá (1990-2017). Produzido em 08/12/2019.

A imagem classificada acima trouxe os seguintes dados de vegetação (representada pela cor verde), área urbana (cor vermelha), solo exposto (cor amarela) e água (cor azul), conforme tabela 02:

Tabela 02: Porcentagem das classes de vegetação, área urbana, solo exposto e superfície de água, utilizandose a técnica de Máxima Verossimilhança (MAXVER).

\begin{tabular}{ccccc}
\hline Ano & Vegetação (\%) & Área urbana (\%) & Solo exposto (\%) & Água (\%) \\
\hline 1990 & 25,02 & 24,11 & 47,82 & 3,03 \\
2000 & 20,36 & 30,06 & 43,02 & 6,56 \\
2017 & 17,20 & 37,84 & 42,58 & 2,38 \\
\hline
\end{tabular}

A tabela 02 indica, após um comparativo das classes acima em um período de 27 anos, que houve acréscimo de 13,73\% de área urbana, redução de $8 \%$ na vegetação e de $5,24 \%$ nos níveis de solo exposto. Além disso, houve uma oscilação na classe água, subindo inicialmente em 3,53\% até o ano 2000 e, posteriormente reduzindo $4,18 \%$. Esta redução da classe água, quando comparados os anos de 2017 e 2000, ocorre em função da expansão significativa da classe "área urbana".

As áreas extraídas passaram pelo processo de classificação supervisionada (MAXVER) que consiste em atribuir assinaturas multiespectrais aos alvos em superfície, baseado nas informações do usuário. Por fim, esta técnica leva os pontos (pixels) que tiveram atribuídas pelo usuário a mesma assinatura espectral, aos outros pontos idênticos existentes na imagem formando conjuntos de classes.

$\mathrm{Na}$ figura 03, são apresentadas as imagens aéreas do Google Earth ${ }^{\circledR}$ referente ao ano de 2017, sem inclinações, para que não haja interferências na interpretação do aplicativo PCI Geomatics ${ }^{\circledR}$ Free Trial. 
Revista Brasileira de Geografia Física v.13, n.07 (2020) 3254-3274.

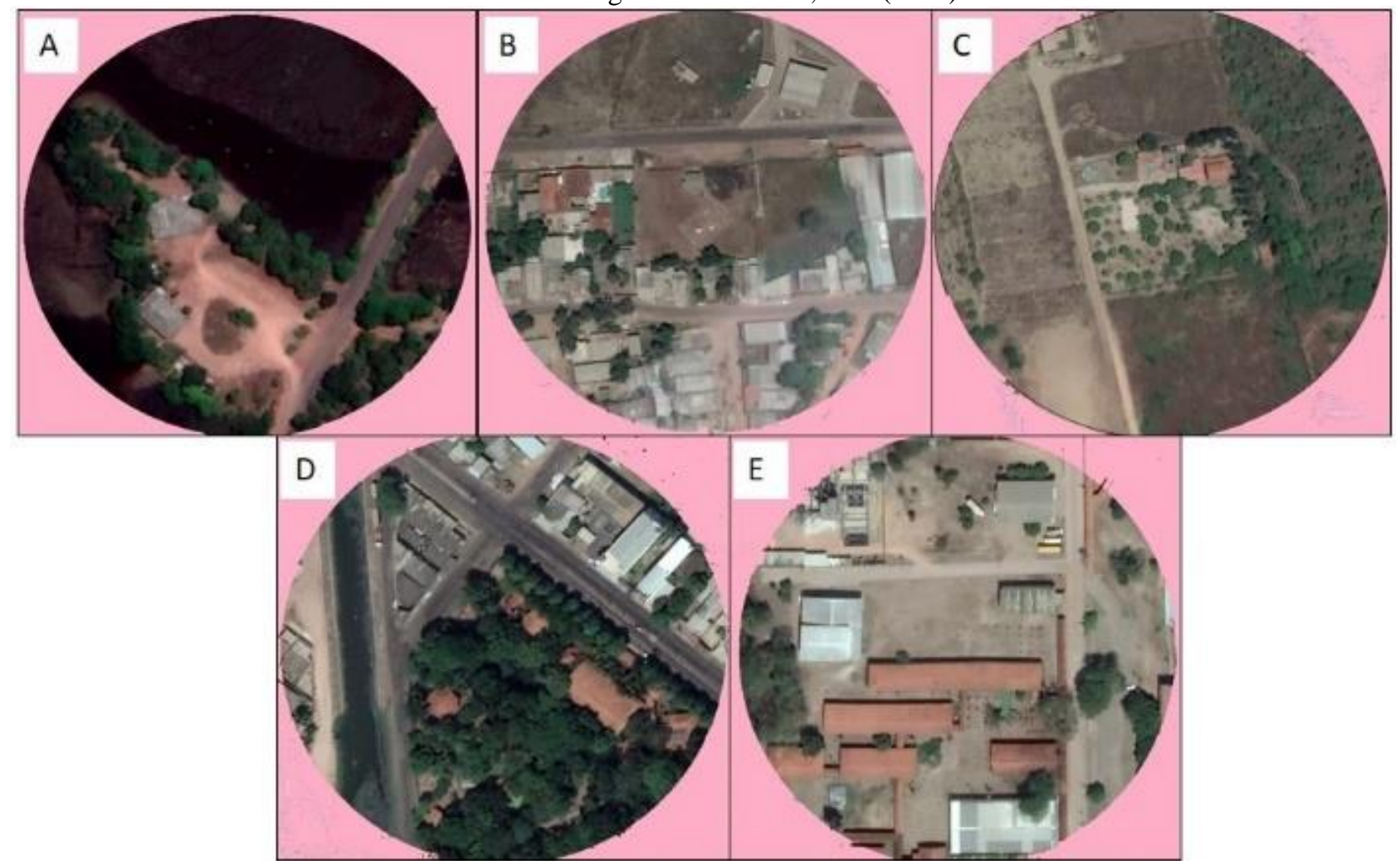

Figura 03: Imagens aéreas dos cinco sítios amostrais de coleta utilizadas para a classificação supervisionada MAXVER, A) APA do Curiaú B) Distrito da Fazendinha, C) Linha B do Marabaixo, D) Museu Sacaca, E) UNIFAP. Produzido em 08/12/2019.

\section{Análises Estatísticas}

Para a organização estatística dos dados foi elaborada uma análise descritiva. Posteriormente foi aplicado um teste de normalidade para avaliar aderência das distribuições dos elementos meteorológicos. Para este propósito foi realizado o teste de Shapiro-Wilk com um nível de significância $(\alpha<0,05)$. Todavia, como a maioria das distribuições dos elementos meteorológicos foram não normais, com o propósito de realizar análises multicomparativas, o método não paramétrico de Friedman foi utilizado. O teste de Friedman é utilizado como uma alternativa não paramétrica para o teste de experimentos em blocos ao acaso (RBD - Randon Blocks Design) na ANOVA convencional (Crawley, 2007; R Development Core Team, 2016). O teste de

\section{Resultados e discussão}

Análise por meio da Classificação Supervisionada de Máxima verossimilhança (MAXVER) nos pontos de coleta.

Ao traçar um raio de $100 \mathrm{~m}$ a partir do sensor instalado em cada ponto, são apresentadas as porcentagens obtidas para as classes vegetação,
Friedman substitui o RBD quando as premissas de normalidade não são garantidos, ou quando as variações são provavelmente diferentes de população para população. Este teste utiliza ranks dos dados ao invés de seus valores brutos para a inferência estatística, além de não impor suposições sobre a distribuição, apesar de não ser tão robusto quanto o teste padrão se as populações forem realmente normais. No presente caso, o método de Friedman foi aplicado para testar se os resultados experimentais são significativamente distintos (T e UR). Desta forma, o teste de Friedman comparou as variações dos elementos meteorológicos, tanto em nível espacial (cinco estações distintas) quanto em nível sazonal (três períodos distintos) (Tabela 04).

solo exposto, área urbana e superfície de água por meio desta metodologia (tabela 03).

A estimativa das percentagens permite realizar uma análise detalhada a respeito da interpretação da variação da temperatura do ar e da umidade relativa do ar nos pontos analisados. A imagem é do ano de 2017, mais atualizada do Google Earth Pró® na época da pesquisa. 
Revista Brasileira de Geografia Física v.13, n.07 (2020) 3254-3274.

Para o presente trabalho foram criadas quatro classes de análise, definidas: "Vegetação", "Área Urbana", "Solo Exposto" e "Água", tendo a classe "vegetação" englobando as espécies arbóreas e gramíneas. A classe "Área Urbana" englobou as superfícies cimentícias, asfalto, edificações em geral.
A classe "Solo Exposto", consiste nas ruas de terra, solo sem superfície vegetada ou urbanizada.

Por fim, a classe relacionada a água são os corpos hídricos em geral, rios, lagos e até piscinas (Silva Junior, 2012).

Tabela 03: Porcentagem das classes vegetação, área urbana, solo exposto e superfície de água, encontrados por meio da técnica de Máxima Verossimilhança nos pontos de coleta.

\begin{tabular}{lccccc}
\hline \multicolumn{1}{c}{ SÍTIO (\%) } & UNIFAP & Museu Sacaca & Marabaixo & APA do Curiaú & Fazendinha \\
\hline Área Urbana & 47,74 & 54,41 & 1,68 & 16,53 & 37,63 \\
Vegetação & 16,85 & 33,41 & 17,56 & 54,36 & 13,76 \\
Solo exposto & 35,38 & 2,68 & 80,60 & 15,08 & 48,54 \\
Água & 0,02 & 9,49 & 0,16 & 14,01 & 0,05 \\
\hline
\end{tabular}

Os resultados obtidos demonstram uma variação acentuada das classes área urbana, vegetação, solo exposto e água nas áreas analisadas. Por exemplo, os pontos que apresentam com maior cobertura urbana foram o Museu Sacaca, a UNIFAP e a Fazendinha.

Por sua vez, os pontos mais vegetados são: a APA do Curiaú $(54,36 \%)$ e o Museu Sacaca $(33,41 \%)$. Esta última é considerada uma área vegetada, porém tendo como entorno uma área urbana consolidada.

Destacam-se ainda, os pontos que apresentam uma composição acentuada de solo exposto, sendo elas o Marabaixo (80,60\%), Fazendinha $(48,54 \%)$ e UNIFAP com $35,38 \%$.

No aspecto da água destacam-se apenas a APA do Curiaú $(14,01 \%)$ e o Museu Sacaca $(9,49 \%)$, sendo que outros pontos apresentaram pouquíssima ou nenhuma porcentagem desta categoria, estando mais ligadas a presença de piscinas artificiais, como ocorrido no Marabaixo $(0,16 \%)$, Fazendinha $(0,05 \%)$ e na UNIFAP $(0,02 \%)$.

Sazonalidade da temperatura do ar e da umidade relativa do ar em locais com diferentes tipos de uso e ocupação do solo.

Baseado nos resultados obtidos na tabela 04, é possível avaliar a sazonalidade da temperatura do ar e da umidade relativa do ar quantificadas nas três campanhas de campo realizadas durante os períodos seco, úmido, transiente, destacando-se as características de cada estação meteorológica e a localização dos pontos mais arborizados e menos arborizados.

A ênfase da análise ocorre normalmente só em períodos secos, quando o fenômeno da ICU torna-se mais evidente. Mas, segundo Roth (2007) são as mais propícias à formação ICU, pois a estação chuvosa tende a homogeneizar a temperatura do ar em decorrência da maior disponibilidade de vapor d'água.

Após um teste de normalidade (ShapiroWilk) observou-se que parte significativa das distribuições das amostras não eram normais $(p<0,05)$. Por este motivo foi utilizado o teste multicomparativo não paramétrico de Friedman (Costa et al., 2018). O objetivo foi testar se os resultados experimentais são significativamente distintos (T e UR) $(\alpha<0,05)$. Desta forma o teste de Friedman compara as diferentes variações dos elementos meteorológicos, tanto em nível espacial (cinco estações distintas) quanto em nível sazonal (três períodos distintos) (Tabela 04).

Os pontos mais quentes, no período úmido, são os mais urbanizados da cidade, conforme MAXVER: As localidades são a Fazendinha $\left(26,21{ }^{\circ} \mathrm{C}\right)$ e o Museu Sacaca $\left(25,89^{\circ} \mathrm{C}\right)$, enquanto o menos urbanizado possui menor temperatura, como a Linha B do Marabaixo $\left(24,47^{\circ} \mathrm{C}\right)$.

A umidade relativa do ar apresenta significância estatística em todos os três períodos da campanha experimental, isto é, variação espacial significativa, com destaque para a localidade do Distrito da Fazendinha (sul da capital) e Linha B do Marabaixo (oeste da capital). Enquanto isso, a temperatura do ar não apresenta tal significância no campo realizado no período seco e intermediário. Contudo, apresenta significância no período úmido, quando as três campanhas experimentais são consideradas globalmente. Isto indica que outro(s) fator(es) tenha(m) mais interferência do que a vegetação nas temperaturas dos locais analisados. Entre estes fatores, por exemplo, as 
Revista Brasileira de Geografia Física v.13, n.07 (2020) 3254-3274.

brisas fluviais têm sido recorrentemente citadas, além do albedo de superfície, a temperatura do solo, dentre outros.

Tabela 04: Medianas das três campanhas de campo simultâneas referentes à temperatura do ar (T) e umidade relativa do ar (UR)

\begin{tabular}{|c|c|c|c|c|}
\hline \multicolumn{5}{|c|}{ Teste de Friedman $(\alpha<0,05)$ (Temperatura do $\operatorname{ar}\left({ }^{\circ} \mathrm{C}\right) /$ Umidade relativa do $\left.\operatorname{ar}(\%)\right)$} \\
\hline & Período úmido (U) & Período & Período seco (S) & Média Total \\
\hline \multicolumn{5}{|c|}{ Intermediário (I) } \\
\hline SACACA & $25,89 / 91,36$ & $27,63 / 85,21$ & $29,70 / 73,35$ & $27,40 / 84,64$ \\
\hline MARABAIXO & $24,47 / 95,65$ & $26,26 / 85,42$ & $28,38 / 68,10$ & $26,53 / 83,46$ \\
\hline FAZENDINHA & $26,21 / 84,30$ & $27,51 / 79,96$ & $29,99 / 69,05$ & $28,02 / 78,06$ \\
\hline CURIAÚ & $25,39 / 91,84$ & $26,68 / 87,96$ & $28,62 / 72,82$ & $26,26 / 84,24$ \\
\hline UNIFAP & $24,87 / 96,03$ & $27,78 / 85,15$ & $29,63 / 75,24$ & $27,61 / 84,76$ \\
\hline p-valor & $<0.0012 /<0.0012$ & $<0.2329 /<0.0458$ & $<0.1608 /<0.0064$ & $<0.0002 /<0.0000$ \\
\hline Friedman chi-squared & $17,9 / 17,9$ & $5.5782 / 9.7$ & $6.5641 / 14.3$ & $21.538 / 35.6$ \\
\hline DF & $4 / 4$ & $4 / 4$ & $4 / 4$ & $4 / 4$ \\
\hline
\end{tabular}

Neste sentido, Kuhn et al. (2010), destaca o efeito das brisas fluviais do Rio Amazonas e dos mecanismos de grande escala como a Zona de Convergência Intertropical (ZCIT), que influenciam significativamente as condições de tempo e clima na região (ventos preferenciais de Nordeste-Sudoeste - na direção e sentido de maior extensão urbana da cidade), de modo que a precipitação e os padrões de umidade relativa do ar e temperatura do ar deixem de ocorrer em períodos conhecidos, o que pode justificar, os valores estatisticamente não significativos nos períodos seco e intermediário, exceto no período chuvoso. 

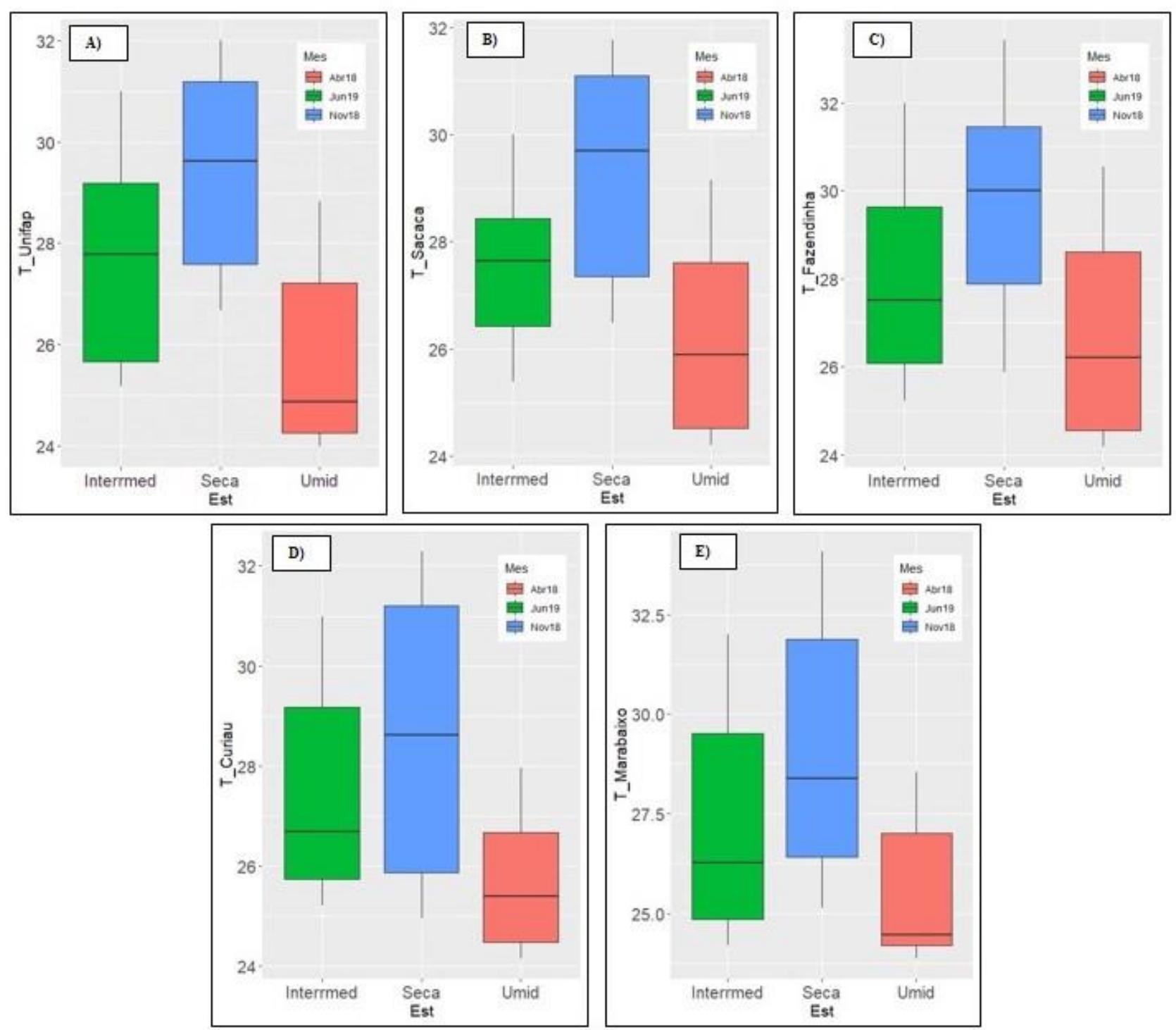

Figura 04: Resultados comparativo da variação sazonal da temperatura (T) obtidas nos períodos (Est) intermediário (intermed) seco (seca) e úmido (umid) para cinco estações meteorológicas semiautomáticas: UNIFAP (A); Museu Sacaca (B), Distrito da Fazendinha (C), APA do Curiaú (D) e Linha B do Marabaixo (E).

No período seco, os locais com menor mediana de temperatura são a Linha B do Marabaixo $\left(28,38{ }^{\circ} \mathrm{C}\right)$, seguida pela APA do Curiaú $\left(28,62{ }^{\circ} \mathrm{C}\right)$, em decorrência da baixa urbanização e da alta arborização, respectivamente. Por sua vez, as maiores temperaturas ocorreram no Museu Sacaca $\left(29,70{ }^{\circ} \mathrm{C}\right)$ e no Distrito da Fazendinha $\left(29,99^{\circ} \mathrm{C}\right)$, dada à grande porcentagem de área urbana existente, embora o primeiro seja uma grande área arborizada. As estações mais chuvosas tendem a apresentar registros de ICU mais fracas do que nas estações mais secas, como abordado por Amorim e Dubreuil (2017).

Destaca-se a estação seca, que apresentam as maiores temperaturas, dada a menor porcentagem de vapor d'água e a maior incidência de energia. No Museu Sacaca (Figura 04-B), predominam temperaturas mais altas durante parte do dia, em decorrência da alta urbanização no seu entorno, o que demonstra a importância da localização do Museu bem arborizado na região central da cidade, que ameniza os efeitos do desconforto térmico.

O Distrito da Fazendinha (Figura 04-E), embora localizada na periferia da cidade, apresenta um baixo índice de arborização e alta porcentagem de solo exposto no raio analisado, o que justifica apresentar a maior mediana de temperatura de todos os pontos analisados. Sanches et al. (2018), obteve uma variabilidade parecida na estação mais quente em Uberaba-MG, onde os espaços mais densamente urbanizados passaram a ter maior exposição a radiação solar, contribuindo para o aumento da temperatura do ar destes pontos em 
Revista Brasileira de Geografia Física v.13, n.07 (2020) 3254-3274.

virtude dos materiais que constituem este espaço (concreto, asfalto). Neste sentido, Santiago e Gomes (2016), utilizando mapas de Índice de Vegetação por Diferença Normalizada (IVDN) obtiveram valores maiores de temperatura de superfície em áreas densamente urbanizadas, tendo diferenças de $8^{\circ} \mathrm{C}$ em relação às áreas rurais do município de Maceió-AL, demonstrando uma relação inversamente proporcional entre os índices de vegetação e a temperatura de superfície.

A Linha B do Marabaixo (Figura 04-C), pela grande quantidade de solo exposto $(80,60 \%)$, apresenta um boxplot mais alongado, visto que este tipo de solo absorve e perde energia rapidamente em comparação com as áreas mais vegetadas, como indicado por Leite et al. (2018). Este ponto apresenta uma mediana mais baixa em relação aos outros pontos, porém apresenta em determinadas horas do dia, na estação seca, temperaturas próximas a $34^{\circ} \mathrm{C}$.

$\mathrm{Na}$ figura 05 , constam graficamente os resultados obtidos para a Umidade relativa do ar, já descritos na tabela 04 .
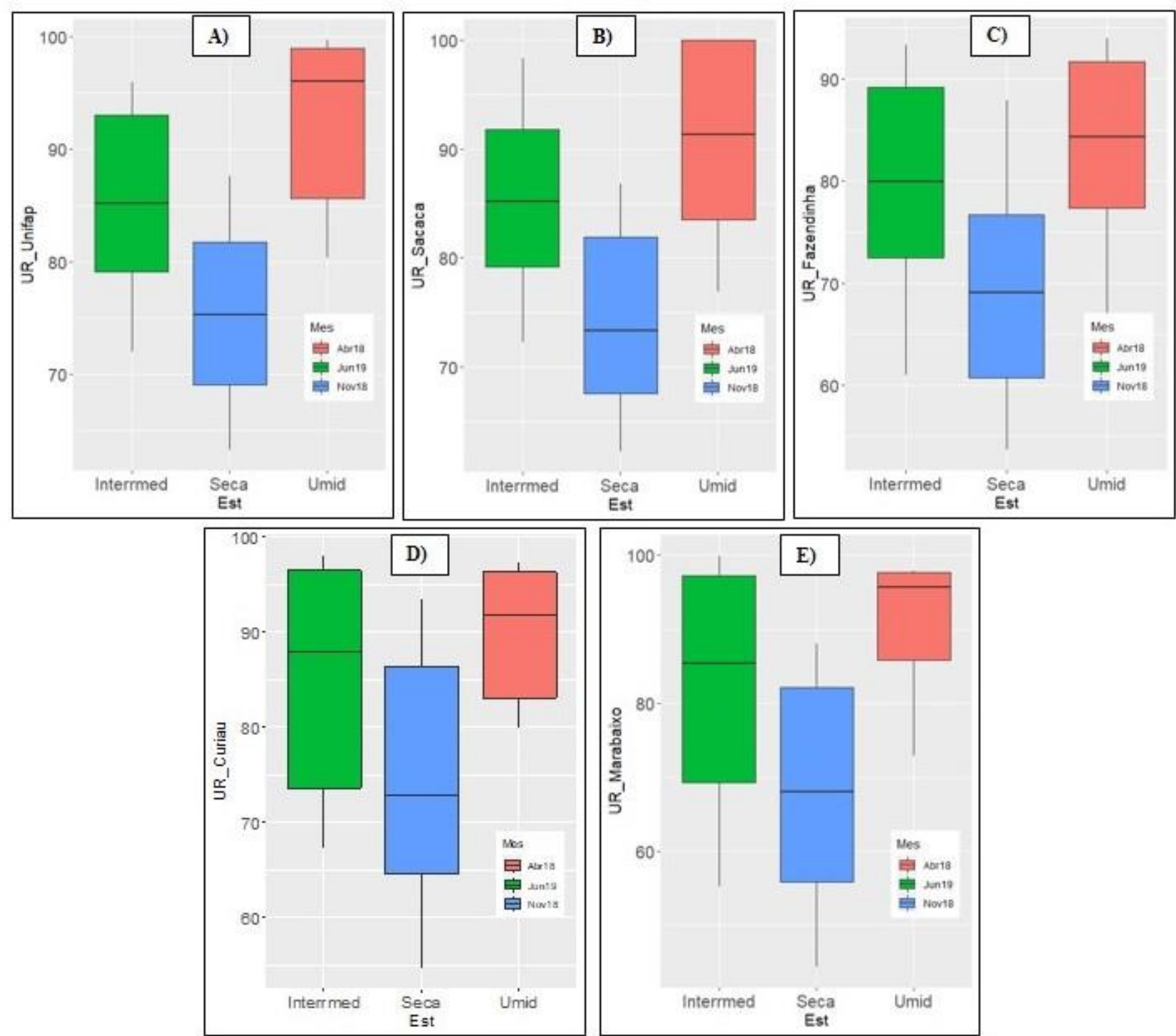

Figura 05: Resultados comparativo da variação sazonal da Umidade relativa do ar (UR) obtidas nos períodos (Est) intermediário (intermed) seco (seca) e úmido (umid) para cinco estações meteorológicas semiautomáticas: UNIFAP (A); Museu Sacaca (B), Distrito da Fazendinha (C), APA do Curiaú (D) e Linha B do Marabaixo (E).

Em geral, as medianas de UR apesentaram valores maiores no período úmido, pela maior porcentagem de vapor d'água presente na atmosfera, que tende inclusive a reduzir as 
Revista Brasileira de Geografia Física v.13, n.07 (2020) 3254-3274.

diferenças térmicas entre os pontos. O período seco a temperatura do ar, pela menor disponibilidade de vapor d'água, tende a sofrer maior influência do ambiente, acentuando as diferenças térmicas, como apontado por Barbosa et al. (2015).

A APA do Curiaú (Figura 05-D), apresentou em alguns momentos do dia UR próxima a $100 \%$, ocorridos no horário entre às 06 e 08:00, nas estações úmida e intermediária. $\mathrm{Na}$ estação seca, por sua vez, há ocorrência de dados próximos a 50\% entre 12:00 e 15:00, e, na estação intermediária em outros horários do dia, ocorrem valores médios de $65 \%$. Esta UR mais alta é explicada pela grande presença de áreas vegetadas $(54,36 \%)$ e também de corpos hídricos $(14,01 \%)$, o que tende a suavizar os efeitos da ICU e do eventual desconforto térmico em períodos de maior incidência solar, dependendo do local.

O ponto do Museu Sacaca apresenta UR média de $85,21 \%$. Neste ponto (Figura 05-B) fica demonstrada a importância da arborização, pois mesmo localizada em uma área densamente urbanizada, por ser uma área verde, apresenta UR maior em relação ao Distrito da Fazendinha e a Linha B do Marabaixo.

A UNIFAP (Figura 05-A) apresenta a segunda maior oscilação, variando de registros de

Diferenças térmicas entre os pontos extremos com relação a cobertura vegetal.

A Figura 06 apresenta a variabilidade média diária da temperatura do ar a cada intervalo de três horas, no período seco, somente entre os pontos vegetados, pouco vegetados e sob solo exposto. A escolha do período seco ocorreu pela
$100 \%$ no período úmido para aproximadamente $55 \%$ no período seco, o que é explicado pela grande porcentagem de solo exposto $(35,38 \%)$ e fraca presença de vegetação $(16,85 \%)$ dentro do raio analisado.

No período seco especificamente, o Distrito da Fazendinha e a Linha B do Marabaixo apresentam menores índices de UR. Assim, considerando características semelhantes encontradas em Costa et al. (2013) e Silva Junior et al. (2012b), dentre os pontos analisados, estas duas localidades são as potencialmente mais desconfortáveis termicamente. Contudo, é necessário trabalhos mais detalhados para confirmar esta hipótese.

A maior variação na UR ocorreu no Marabaixo (27,55\%), aparentemente em virtude da maior porcentagem de solo exposto $(80,60 \%)$, como visto na figura $05-\mathrm{E}$.

O Distrito da Fazendinha (Figura 05-C) apresenta uma concentração conjunta de áreas urbanas e solo exposto que totalizam $86,17 \%$, que associadas a baixa cobertura de vegetação $(13,76 \%)$, justificam os menores valores de UR $(79,96 \%)$ ou $5,19 \%$ menos que às demais localidades.

menor porcentagem de vapor d'água, bem como do aumento da incidência de energia nos pontos, o que amplia a influência do uso do solo na temperatura do ar (Silva, 2016).

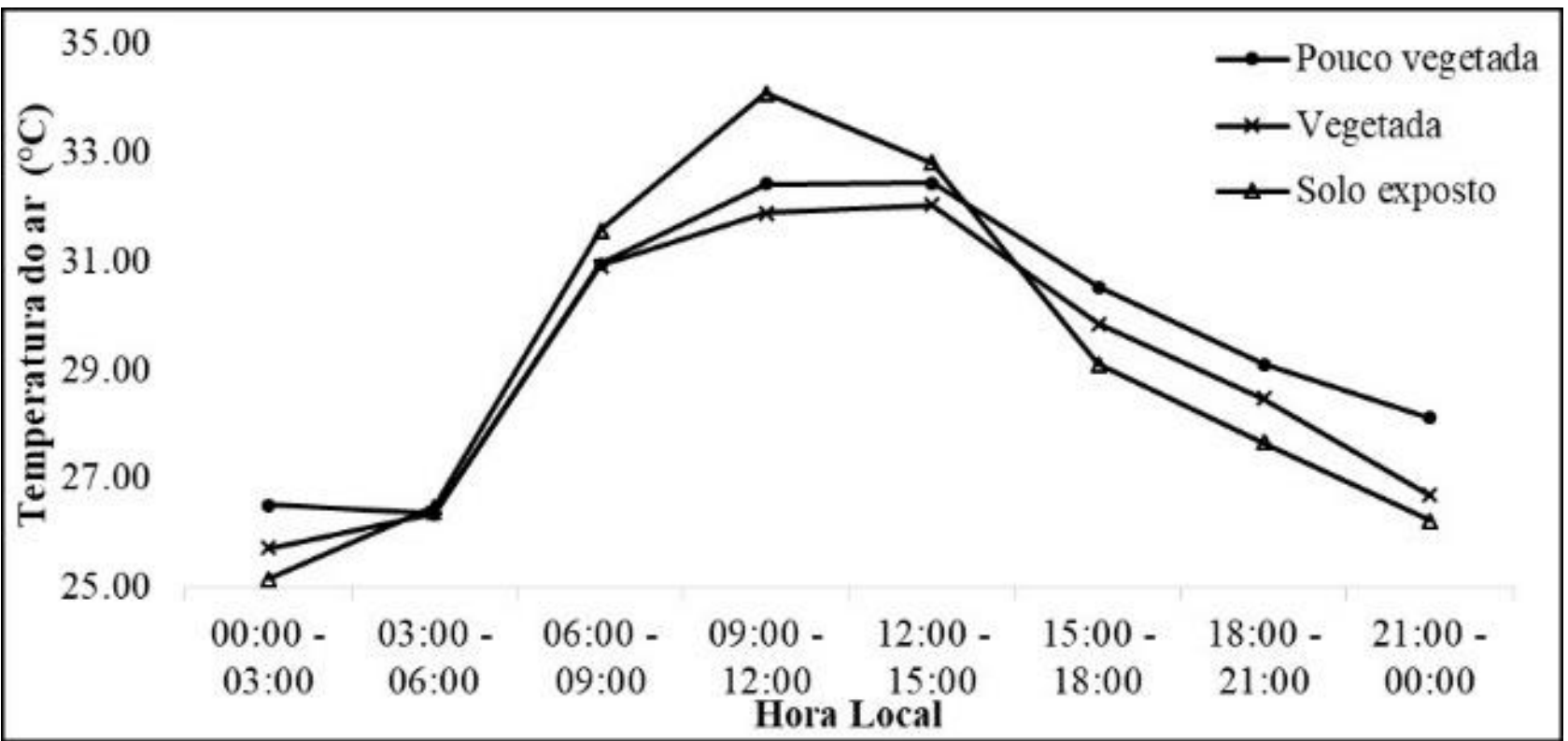

Figura 06: Comparativos da média de temperatura do ar. 
Revista Brasileira de Geografia Física v.13, n.07 (2020) 3254-3274.

As médias foram resultantes das percentagens encontradas nos pontos analisados. Assim as áreas "pouco vegetadas", nos quais as médias foram obtidas são: Fazendinha e UNIFAP; As áreas consideradas vegetadas foram o Museu Sacaca e a APA do Curiaú. Por fim, devido a variabilidade diferenciada da temperatura do ar na Linha B do Marabaixo, optou-se por criar uma classe exclusiva para este ponto denominada "Solo exposto", ao invés de analisá-la com demais "áreas vegetadas".

$\mathrm{Na}$ figura 06 observa-se que, entre 00:00 e 03:00, diferenças térmicas entre as três médias, resultantes da perda de calor mais lenta nos pontos mais urbanizados, devido aos materiais artificiais e sua maior composição neste tipo de ambiente ser constituída de cimento e asfalto. Os pontos pouco vegetados apresentaram as maiores temperaturas, com diferença aproximada de $0,80{ }^{\circ} \mathrm{C}$ em relação as áreas vegetadas. Esta diferença é maior ainda quando comparada com temperaturas do ar das áreas de solo exposto. E devido a sua capacidade de armazenar calor, o solo exposto apresenta 1,37 ${ }^{\circ} \mathrm{C}$ mais frio em relação as áreas mais urbanizadas.

Entre 03:00 e 06:00, os pontos apresentam temperaturas do ar muito próximas, com as maiores diferenças térmicas. Isso ocorreu entre os pontos pouco vegetados e o solo exposto $\left(0,12{ }^{\circ} \mathrm{C}\right)$, influenciado pela fraca incidência de energia neste período e pela sua dissipação em períodos anteriores do dia.

Entre 06:00 e 12:00, a Linha B do Marabaixo, representado pelo "Solo exposto", com alta porcentagem $(80,60 \%)$, que segundo Leite et al. (2018), é capaz de absorver e perder calor muito rápido, se destaca termicamente em relação às outras áreas, variando de 0,6 a 2,20 ${ }^{\circ} \mathrm{C}$ mais quente em relação as áreas vegetadas e 0,6 a $1,6^{\circ} \mathrm{C}$ mais quente que as áreas arborizadas. Ao mesmo tempo, as áreas pouco vegetadas oscilam até $0,54{ }^{\circ} \mathrm{C}$ mais quentes que as áreas vegetadas, dada a presença proporcionalmente maior de edificações e ao trânsito mais movimentado, corroborando com os dados que Zhu et al. (2017) obteve em seu estudo na China. Entre 12:00h e 15:00h inicia-se a perda rápida de calor no "Solo exposto", pelos motivos explicitados anteriormente, ficando $\mathrm{T}$ próxima daquelas das áreas pouco vegetadas e vegetadas.

Entre 15:00h e 18:00h, as áreas pouco vegetadas tornam-se as mais aquecidas termicamente, devido a presença de áreas urbanas mais concentradas $(37,63 \%$ e $47,74 \%)$ e baixa cobertura vegetal $(13,76 \%$ e $16,85 \%)$. Esse comportamento ocorreu, respectivamente, no Distrito da Fazendinha e na UNIFAP, consideradas "pouco vegetadas". Por exemplo, essas áreas tiveram aquecimento de $0,67{ }^{\circ} \mathrm{C}$ em relação às áreas vegetadas (média do Museu Sacaca e da APA do Curiaú) e $1,42{ }^{\circ} \mathrm{C}$ em relação ao solo exposto. As Áreas de solo exposto passaram a ser termicamente mais frias, devido a rápida perda de energia e em função do calor específico menor da areia em relação à vegetação e aos materiais antrópicos (cimento, asfalto, dentre outros).

De 18:00h a 21:00h, a área de solo exposto continua sendo mais fria, cuja variabilidade se mantém até o fim do dia. No entanto, a diferença térmica entre a área pouco vegetada e a área vegetada aumenta, com valores entre 0,64 e 0,67 ${ }^{\circ} \mathrm{C}$, indicando que realmente os níveis de vegetação influenciam no aquecimento térmico da área, justamente pela perda mais lenta de calor que ocorre nas áreas mais urbanizadas, variabilidade esta indicada por Barbosa et al. (2015), analisando diferentes localidades da Amazônia: Belém-PA, Manaus-AM e na Floresta Nacional do Caxiuanã.

Entre 21:00h e 00:00h, as áreas pouco vegetadas ficaram $1,42{ }^{\circ} \mathrm{C}$ mais quente em relação as áreas mais vegetadas, e $1,89^{\circ} \mathrm{C}$ em comparação às áreas de solo exposto. As áreas mais vegetadas tendem a perder calor mais rapidamente do que as áreas mais centrais e urbanizadas. Outro aspecto importante, é que o Museu Sacaca, embora localizado em área de urbanização consolidada e edificada $(54,41 \%)$, possui uma significativa percentagem de vegetação $(33,41 \%)$, que produz um resfriamento térmico o que torna a temperatura local mais amena, reforçando a hipótese da necessidade de mais áreas verdes em locais intensamente urbanizados, evidenciando as zonas mais quentes durante períodos noturnos, que segundo Leal filho et al. (2017), recomendam o bom uso da vegetação para mitigação dos efeitos da ICU.

Amorim e Dubreuil (2017) demonstram que a evolução da ICU varia tanto sazonalmente, conforme a época do ano, quanto de acordo com a hora. Em Presidente Prudente-SP, os autores detectaram ICUs acima de $6{ }^{\circ} \mathrm{C}$ na estação mais seca.

Estes resultados evidenciam a influência do uso e ocupação do solo nos padrões de temperatura do ar, embora nas campanhas de períodos seco e intermediário haja potencialmente fatores de meso e macro escala climáticas que possam estar interferindo significantivamente no microclima local. 
Revista Brasileira de Geografia Física v.13, n.07 (2020) 3254-3274.

Sazonalidade horária média para a ilha de calor urbana durante o período seco.

Segundo Oke (1987), para detectar o fenômeno da ilha de calor, esta deve ser calculada pela diferença entre a temperatura urbana (maiores edificações, trânsito de veículos e pessoas) e a temperatura do seu entorno, podendo ser uma área rural (em geral mais arborizada, com menor trânsito), conforme equação ICU $=\Delta T u-r$.

Nesta seção, para representar a hipótese de diferenciação entre zona urbana típica e zona rural típica e, portanto, para entender a sazonalidade da ICU em Macapá, foram analisadas as diferenças térmicas entre a UNIFAP e a APA do Curiaú.

Estes pontos são considerados, respectivamente, como de características eminentemente urbanas, com baixa arborização e de caracteristicas periféricas, com elevado nível de arborização. Nota-se que estes fatores são importantes para a análise da ICU, como avaliado por Silva (2016). Essas diferenças são explicitadas nas figuras 07 e 08 .

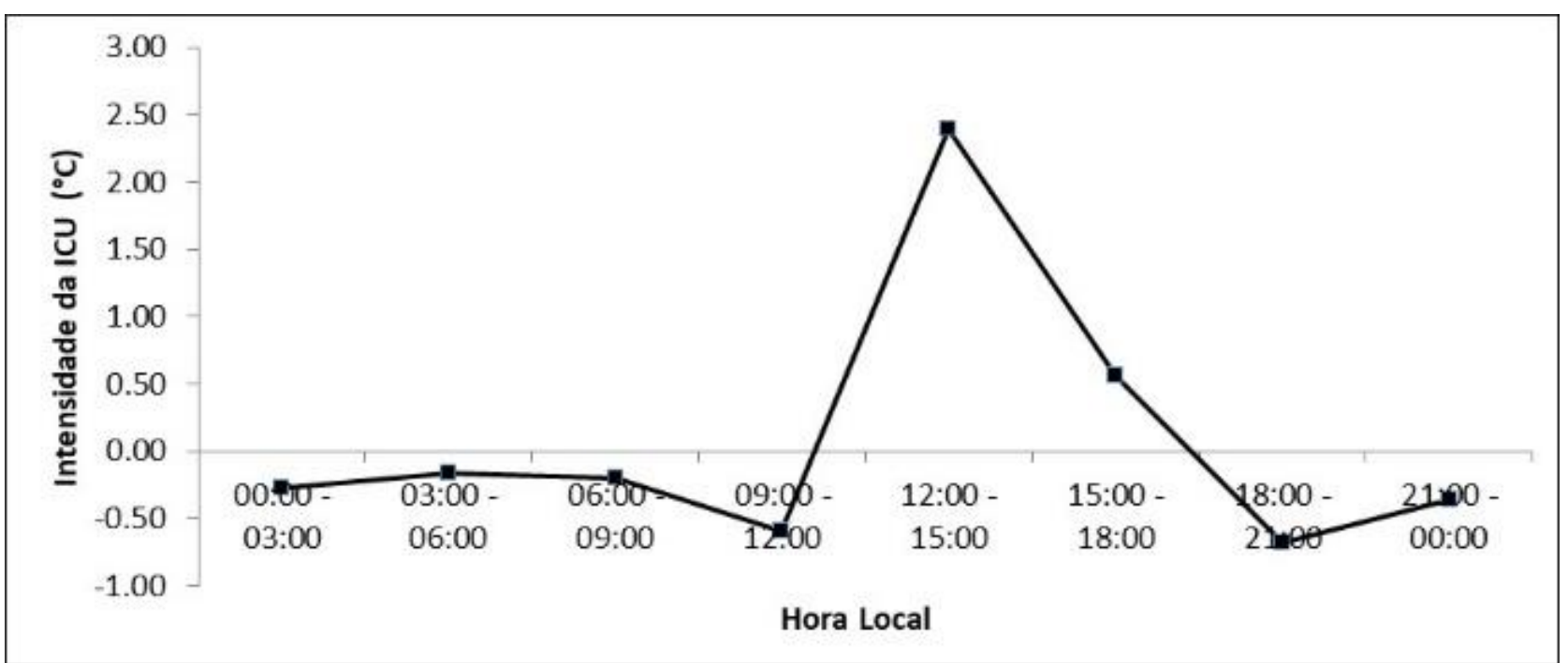

Figura 07: Variabilidade média horária da ilha de calor urbana na cidade de Macapá, referente ao período úmido da Região.

A variabilidade da ICU na época chuvosa, na comparação entre os pontos da UNIFAP apresentou-se da seguinte forma: de 00:00h a 12:00h e de 18:00h a 00:00h o sítio APA do Curiaú apresentou-se mais aquecido que o sítio da UNIFAP, enquanto este tornou-se mais quente que a APA do Curiaú no período entre 12:00h e 18:00h. Apesar disso, entre 00:00h e 06:00h, as diferenças entre os pontos não chegaram a $0,3{ }^{\circ} \mathrm{C}$, indicando parcial homogeneidade entre as diferenças de temperatura. Este padrão foi também detectado por Silva Junior (2012b) em uma análise similar para a cidade de Belém (PA), em que nos períodos chuvosos a temperatura do ar entre as áreas urbana e periférica tendem a se tornar mais próximas.

$\mathrm{Na}$ figura 08, do período seco, por sua vez, verificou-se uma mudança na variabilidade entre os dois sítios amostrais. O sítio UNIFAP apresenta maiores temperaturas em relação à APA do Curiaú na maior parte do dia. A exceção ocorre somente no período entre 06:00h e 12:00h, quando a APA do Curiaú é aproximadamente $0,30{ }^{\circ} \mathrm{C}$ mais quente o do que a UNIFAP. Isto ocorre devido à área da UNIFAP ter maior capacidade de armazenar calor do que a APA do Curiaú, em função do elevado porcentual de área urbanizada existente $(47,74 \%$ na UNIFAP e $16,53 \%$ na APA do Curiaú). 


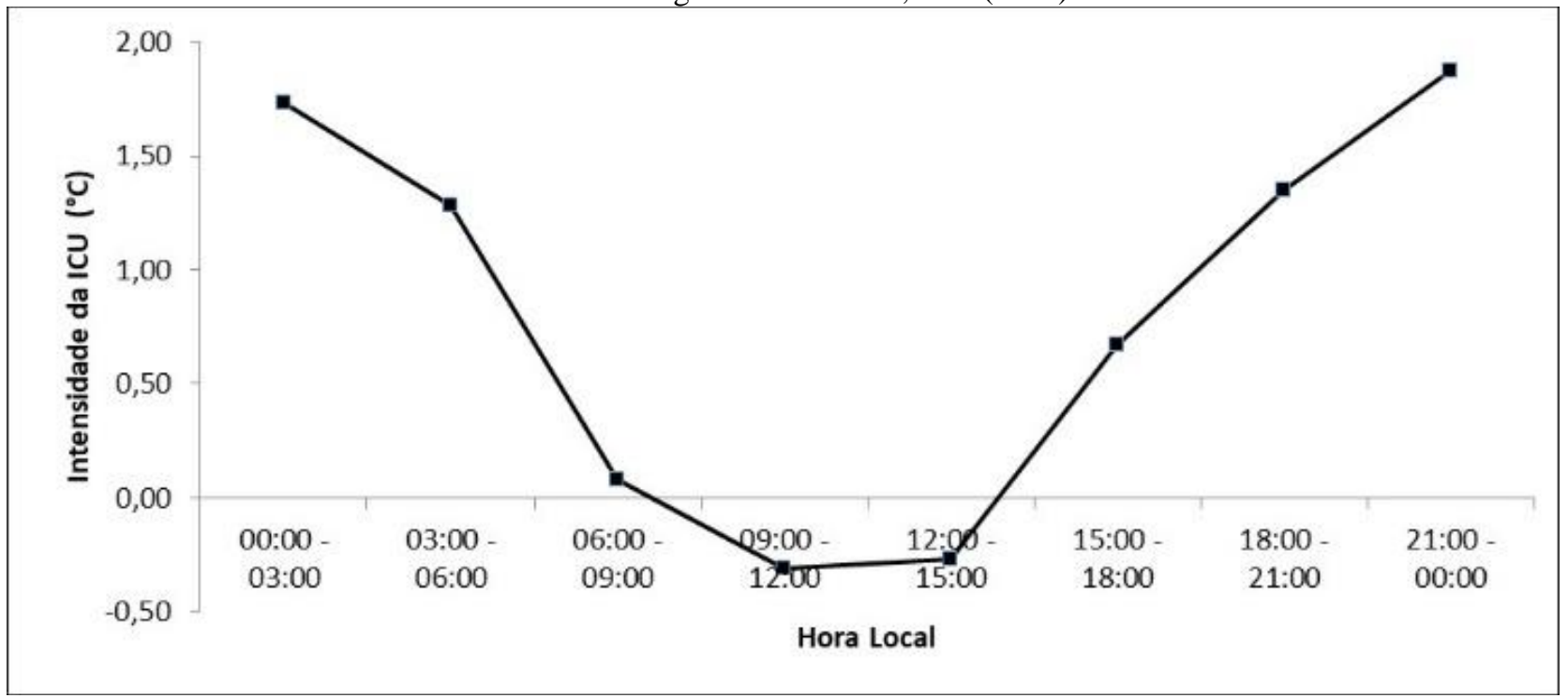

Figura 08: Variabilidade média horária da ilha de calor urbana na cidade de Macapá, referente ao período seco da Região.

A sítio de amostragem da UNIFAP começa a se aquecer a partir do meio-dia mais rapidamente do que a APA do Curiaú. Por exemplo, a APA do Curiaú possui $54,36 \%$ de área vegetada e o calor absorvido durante o dia passa a ser dissipado mais lentamente nas áreas mais urbanizadas do que nas mais vegetadas, como afirmam Souza e Alvalá (2014), o que explica porque a partir de 14:00h até 06:00h do dia seguinte a UNIFAP apresenta temperaturas mais altas do que a APA do Curiaú, com pico de aproximadamente $2^{\circ} \mathrm{C}$ de diferença entre ambos. Isto indica que em Macapá o ponto mais central, com menos arborização ou mais urbanizada, apresenta temperaturas do ar mais altas do que as zonas periféricas com altos níveis de vegetação. Silveira e Carvalho (2016), analisando o município de Portalegre-RN, constaram também que a zona urbana central é $2,4^{\circ} \mathrm{C}$ mais quente do que a zona rural ou de parques, denotando a ICU.

Segundo Zhou et al. (2017), no período seco, a oscilação das temperaturas do ar entre os pontos muito arborizados e muito urbanizados tende mais significativa, em relação ao período chuvoso, em decorrencia da maior absorção de energia dos materiais presentes nas zonas mais urbanizadas.

$\mathrm{Na}$ figura 09 estão indicadas diferenças de temperatura do ar para o período de transição ou intermediário. Como comentado anteriormente, esta análise dá um suporte inédito e um melhor entendimento sobre o papel do período de transição na evolução da ICU. A campanha de campo do período intermediário foi executada em junho de 2019, com maior proximidade do período seco.
É possível observar temperaturas do ar entre a zona central urbanizada e a zona periurbana bem arborizada muito próximas, de 00:00h até 18:00h. O sítio da UNIFAP passa a apresentar temperatura mais elevada a partir de 18:00h até 00:00h, sendo de $0,91{ }^{\circ} \mathrm{C}$ entre $18: 00 \mathrm{~h}$ e $21: 00 \mathrm{~h}$ e de $1,29^{\circ} \mathrm{C}$ entre 21:00h e 00:00h.

Neste caso, observa-se a perda de calor mais lenta na UNIFAP em relação à APA do Curiaú, pela maior quantidade de edificações, respectivamente $47,74 \%$ e $16,53 \%$. Por outro lado, ocorre a liberação de calor mais rápida nas áreas mais arborizadas, como é o caso da APA do Curiaú $(54,36 \%)$ frente aos $16,85 \%$ da UNIFAP.

$\mathrm{O}$ período intermediário tem uma variabilidade mais próxima do período seco, especialmente entre 18:00 e 00:00, mais propício para identificar a ICU, o que pode ser explicado pelo período de coleta, dois meses antes do início do período seco, e também pelas diferenças de uso do solo entre os dois pontos. Os dados, mesmo no período intermediário, reforçam a existência da ICU, com sua intensidade em determinados momentos semelhante ao período seco.

Dessa forma, considerando aqui um esforço inicial de entendimento e os dados obtidos estatísticamente não significativos de Temperatura do ar para o período intermediário, os autores deste trabalho reforçam a importância de se desenvolver pesquisas, visando entender correlações entre os mecanismos de meso e macroescala e a ICU local, como as brisas fluviais do Rio Amazonas, especificadas por Kuhn et al. (2010). 


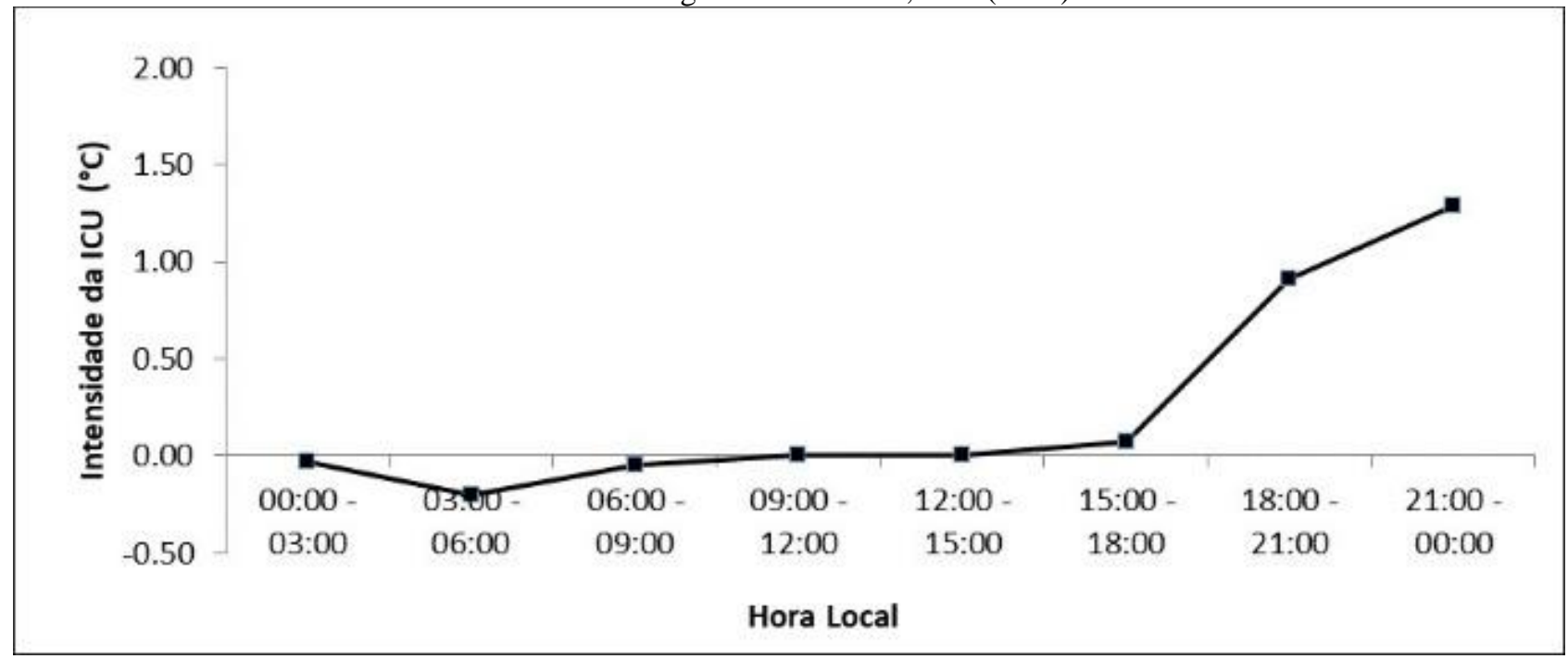

Figura 09: Variabilidade média horária da ilha de calor urbana na cidade de Macapá, referente ao período intermediário da Região.

Relação entre temperatura do ar x cobertura vegetal e urbanização.

Neste item são apresentadas algumas análises específicas sobre a influência de áreas vegetadas e urbanizadas, em relação à temperatura do ar. Foi escolhido o periodo seco, em que os efeitos da ICU são mais intensificados pela menor disponibilidade de vapor d'água e maior incidência de energia, conforme aferido por Costa et al. (2013). Na figura 10 é apresentada uma regressão linear entre as variáveis cobertura vegetal e a temperatura do ar em Macapá, com o objetivo de avaliar seu efeito indireto em ICU.

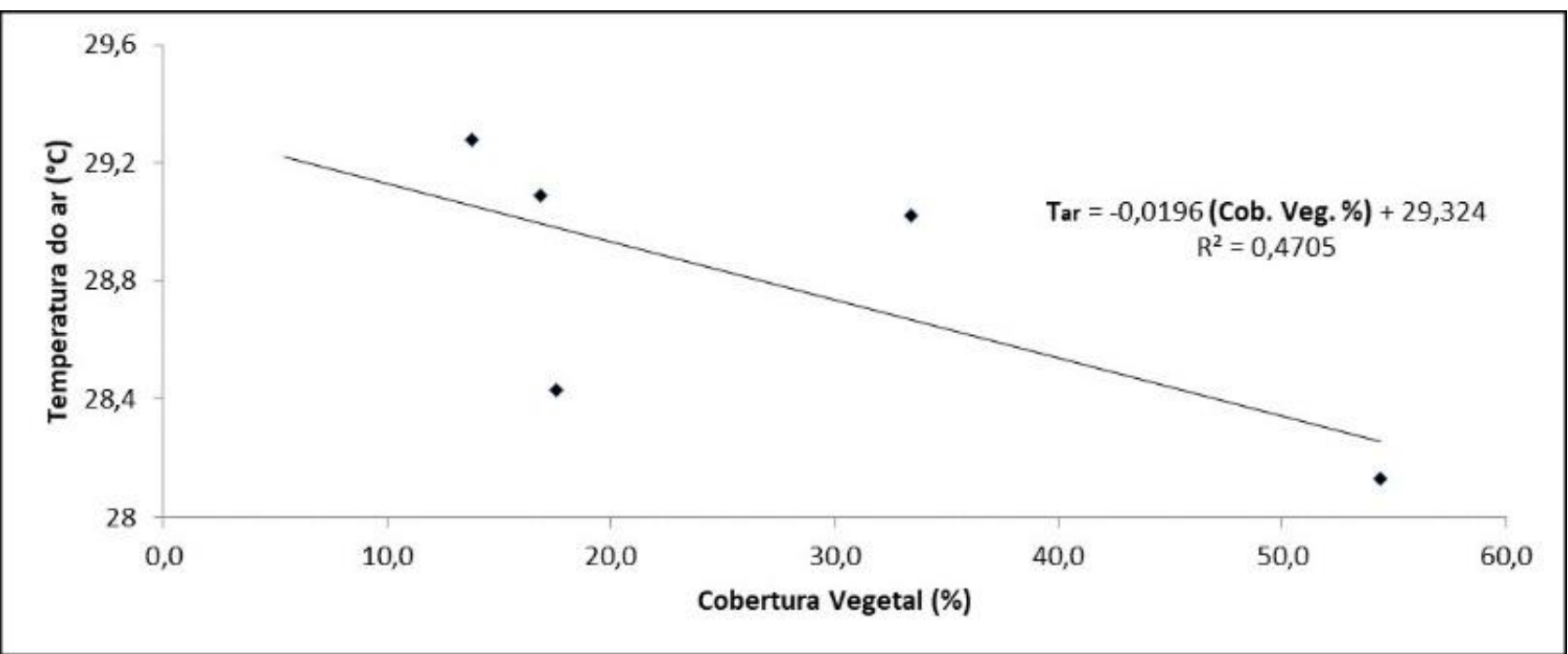

Figura 10: Regressão linear entre a temperatura média diária do ar $\left({ }^{\circ} \mathrm{C}\right)$ e a porcentagem de cobertura vegetal (\%) na zona urbana de Macapá-AP para o período seco.

Quando são testadas as regressões entre as temperaturas médias, máximas e mínimas do ar com a cobertura vegetal existente na cidade, apresentam coeficiente de determinação $\mathrm{R}^{2}=0,47$ (figura 9). E pode ser observado na curva de regressão linear que a variação ou taxa de diminuição das temperaturas médias é negativa e decresce em torno de $-1,96 \%$ para cada incremento percentual de arborização. Neste sentido, Silva Junior et al. (2012a) demonstraram no estudo realizado na cidade de Santarém-PA que a vegetação possui significativa influência nos padrões de uso do solo urbano e indiretamente com $\mathrm{T}\left(\mathrm{R}^{2}=80 \%\right)$. Alves e Lopes (2017) ao simularem modelos com a ampliação do Índice de Vegetação sobre áreas mais urbanizadas em Iporá-GO, obtiveram expressiva redução da temperatura do ar, com a presença inclusive de ilhas de frescor urbanas, corroborando com os resultados deste estudo. 
Revista Brasileira de Geografia Física v.13, n.07 (2020) 3254-3274.

Uma segunda regressão, agora com as esperado comportamento inverso em relação à taxas de urbanização ou cobertura artificial sobre a temperatura do ar, mostrada na figura 11 , sugere o expansão urbana (cobertura).

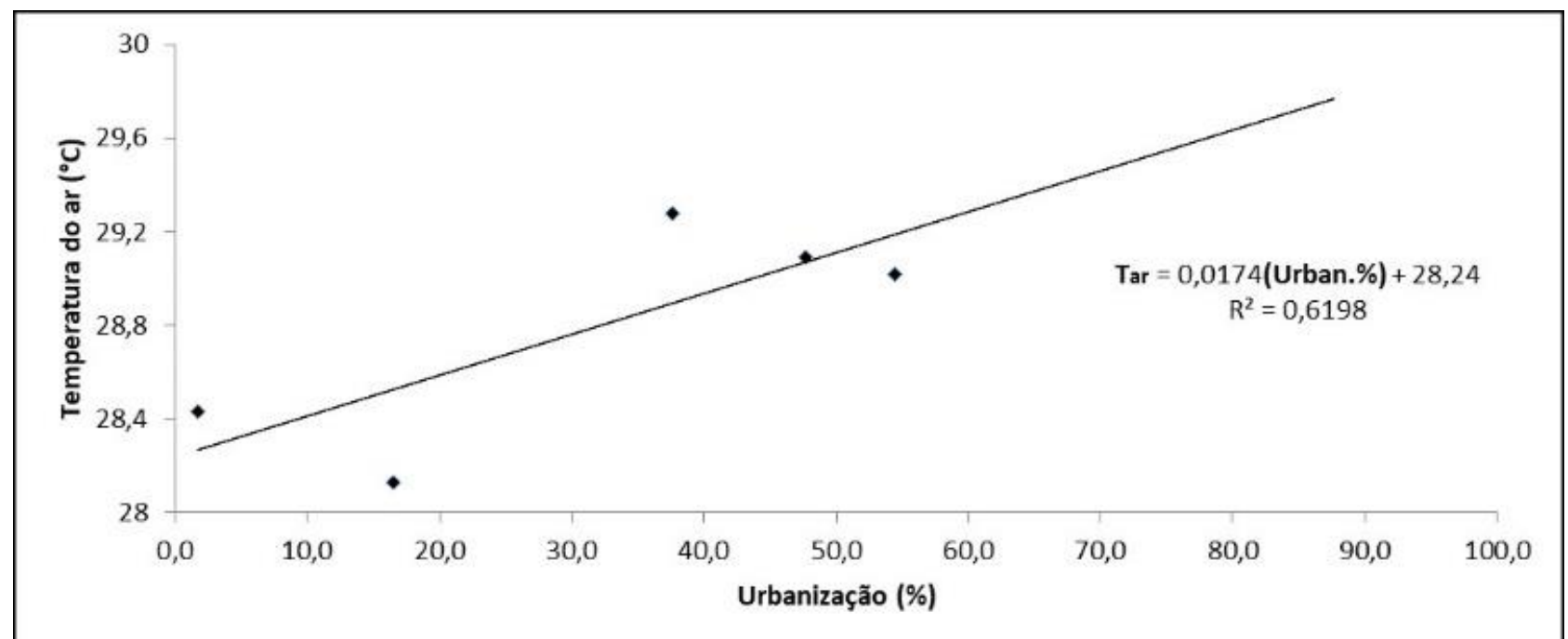

Figura 11: Regressão linear entre a temperatura média diária do $\operatorname{ar}\left({ }^{\circ} \mathrm{C}\right)$ e a porcentagem de urbanização $(\%)$ na zona urbana de Macapá-AP para o período seco.

Quando são testadas as regressões entre as temperaturas médias do ar com os elementos da estrutura urbana, como as edificações, ruas asfaltadas e calçamento, verifica-se que o valor do coeficiente de determinação é igual a $\mathrm{R}^{2}=62 \%$. Isso significa também dizer que o efeito da cobertura artificial do solo é positivo e crescente, de aproximadamente $1,74 \%$ a cada incremento unitário de $\mathrm{T}$. Isto é, para cada percentual de alteração do uso do solo há um efeito incremental proporcional de T. Contudo essa taxa, em termos absolutos, é menor do que a do efeito negativo de cobertura vegetal sobre a T. Disso, subentende-se que a diferença relativa entre ambos os impactos (redução e aumento de $\mathrm{T}$, respectivamente indicada pelas figuras 10 e 11) é de aproximadamente $11,22 \%$, significando que, para uma mesma área de solo, o efeito de rebaixamento da temperatura é mais significativo do que o efeito contrário de aquecimento urbano, com cerca de $11,22 \%$ de diferença em favor do resfriamento.

Estes resultados mostram que se for mantida pelo menos minimamente a proporcionalidade das áreas vegetadas/ocupadas, corroborando com Leal Filho et al. (2017), haverá um "reequilíbrio" em favor da redução da temperatura, evitando-se o desequilíbrio térmico exagerado das ICU pelo excessivo efeito das áreas ocupadas.

\section{Conclusões}

Após análise dos três trabalhos de campo, verificou-se que no período chuvoso a temperatura do ar, quando comparados os sítios amostrais periféricos e urbanos (teste de Friedman), apresenta mais homogeneidade do que nos períodos secos. Isto se deve à maior influência da umidade relativa do ar nesse período, o que tende a diminuir a intensidade da ICU.

Apesar disso, as áreas mais vegetadas, em especial as de menor densidade de edificações, tendem a apresentar menores temperaturas do ar. Mas no período seco, essas diferenças tendem a se acentuar porque a vegetação influi reduzindo a variação e amplitude da temperatura do ar urbano.

Também foi verificada influência do uso do solo, principalmente para a variação horária de temperatura do ar no período seco. Neste período ocorreram maiores ICU nos sítios mais urbanizados do que as áreas mais vegetadas, especialmente nos horários noturnos. Essas características mostram tendência de perda de calor mais lentas das áreas mais edificadas e pavimentadas porque tendem a armazenar mais calor, liberando-o durante o período noturno.

Dessa forma as hipóteses levantadas foram confirmadas. Isto é, tanto as taxas de urbanização quanto as de vegetação tendem a interferir sobre a T e UR. Porém, ambas apresentam comportamento inverso em relação a outra. Este comportamento foi testado e confirmado, sendo o período seco o que maximiza este efeito.

A taxa de crescimento urbano apresentou comportamento linear e positivo em relação ao aumento da temperatura do ar $\left(\mathrm{R}^{2}=61,98 \%\right)$. De modo contrário, apresentou decrescimento linear, 
Revista Brasileira de Geografia Física v.13, n.07 (2020) 3254-3274.

porém negativo, com a temperatura do ar $\left(\mathrm{R}^{2}=-\right.$ $47,05 \%)$.

Apesar dessas correlações lineares, verificou-se que nos trabalhos de campo nos períodos seco e intermediário não tiveram significância estatística ( $p>0,05)$ quando analisada somente a temperatura do ar. E, mesmo que durante as campanhas de período úmido tenha sido observado significância estatística, deduz-se que algum fatores de grande escala possam estar causando esse efeito em detrimento da influência padrão da zona urbana/vegetada sobre a temperatura do ar local.

Destaca-se mais uma vez, a proximidade da cidade de Macapá em relação ao Rio Amazonas. Por exemplo, a formação da ICU parece ser influenciada por uma suavização causada pelas brisas fluviais. Apesar disso, considerando as três campanhas experimentais de campo conjuntamente, além da campanha de período úmido em relação à temperatura do ar, houve significância estatística. Isto é, nestes períodos confirmou-se a hipótese de evidência da formação do fenômeno da ilha de calor urbana (ICU x T e UR) manifestam-se pelo menos em alguns períodos sazonais do ano. Entretanto, não somente no período Seco. Por exemplo, a localidade Fazendinha pode ser considerada como o sítio amostral mais quente do que os demais. Porém, esse efeito só foi observado com significância durante o período úmido e na análise global. Além disso, em relação à UR, houve variações espaciais e sazonais significativas para todos os três períodos sazonais estudados.

Finalmente, é importante ressaltar que ainda há limitações experimentais impostas pela presente pesquisa. Recomenda-se, para avaliar o comportamento das tendências observadas, novas pesquisas que possam confirmar ou refutar estes resultados. Por exemplo, verificando-se se este é um padrão ou uma exceção para ICU. Sugere-se investigar se houve há ou não influência das brisas fluviais sobre o parâmetro ICU em alguns períodos sazonais, considerando os seus efeitos locais em relação àos fenômenos de mesoescala e macroescala que eventualmente estejam influenciando os elementos meteorológicos na microescala urbana.

\section{Agradecimentos}

$\begin{array}{ccr}\text { Os autores } & \text { agradecem } & \text { ao } \\ \text { LQSMSA/UNIFAP, CNPq } & \text { Processo No. }\end{array}$ 309684/2018-8. Ao Laboratório Estação
Meteorológica, do Instituto de Geociências da Universidade Federal do Pará por disponibilizar os microloggers, bem como os abrigos meteorológicos alternativos para a realização dos três trabalhos de campo.

\section{Referências}

Alves, E.D.L.; Lopes, A. 2017. The urban heat island effect and the role of vegetation to address the negative impacts of local climate changes in a small Brazilian city. Atmosphere [online] 8. Disponível: http://dx.doi. org/10.3390/atmos8020018. Acesso: 25/08/2020.

Amorim, M. C. C. T., DUBREUIL, V., 2017. Intensity of Urban Heat Islands in tropical and temperate climates. Climate [online] 5 . Disponível: http://dx.doi. org/10.3390/cli5040041. Acesso: 13/08/2020.

Arya, S. P., 2001. Introduction to Micrometeorology, $2^{\mathrm{a}}$ ed. Academic Press, Cambridge.

Barbosa, P. H. D.; Costa, A. C. L.; Cunha, A. C.; Silva Junior, J. A.; 2015. Variabilidade de elementos meteorológicos e de conforto térmico em diferentes ambientes na Amazônia brasileira. Revista Brasileira de Climatologia [online] $17 . \quad$ Disponivel: http://dx.doi.org/10.5380/abclima.v17i0.43048. Acesso:14/08/2020.

Corrêa, P. B.; Cândido, L.A; Souza, R. A. F.; Andreoli, R. V.; Kayano, M. T., 2016. Estudo do fenômeno da ilha de calor na cidade de Manaus-AM: Um estudo a partir de dados de sensoriamento remoto, modelagem e estações automáticas. Revista Brasileira de Meteorologia 31, 167-176. Doi: http://dx.doi.org/10.1590/010278631220150012.

Costa, A. C. L, Rodrigues, H. J. B., Silva Junior, J. D. A., Nunes, L. R. C., Moraes, B. C., Costa, A. C., Cunha, A. C., Meir, P.; Malhi, Y., 2018. Variabilidade Horária, Diária e Sazonal da Frequência e Intensidade de Precipitação em uma Floresta Tropical Chuvosa na Amazônia Brasileira. Revista Brasileira de Geografia Física 11, 1290-1302.

Costa, A. C. L.; Silva Junior, J. A.; Cunha, A. C.; Feitosa, J. R. P.; Portela, B. T. T.; Silva, G. G. C.; Costa, R. F., 2013. Índices de conforto térmico e suas variações sazonais em cidades de diferentes dimensões na Região Amazônica. Revista Brasileira de Geografia Física 6, 478487.

Doi: http://dx.doi.org/10.26848/rbgf.v6.3.p478-487

Crawley, M. J., 2007. The R Book. $2^{\mathrm{a}}$ Ed. Imperial College London at Silwood Park. John Wiley \& Sons Ltd, London. 
Revista Brasileira de Geografia Física v.13, n.07 (2020) 3254-3274.

INMET. Instituto Nacional De Meteorologia, 2018. Normais Climatológicas do Brasil 1981-2010. Brasília.

Kuhn, P. A. F.; Cunha, A. C.; Pereira, M. J.; Saraiva J. M. B., 2010. Previsão Numérica Operacional no Estado do Amapá Utilizando o BRAMS. In: Cunha, A. C.; Souza; E. B. De; Cunha, H. F. A. (Orgs.). Tempo, Clima e Recursos Hídricos: Resultados do Projeto REMETAP no Estado do Amapá, Editora do Instituto de Pesquisas Científicas e Tecnológicas (IEPA), Macapá, pp. 61-82.

Leal Filho, W.; Icaza, L. E.; Emanche, V. O.; AlAmin, A. Q., 2017. An Evidence-Based review of impacts, strategies and tools to mitigate urban heat island. International Journal of environment research public health [online] 14(12). Disponível: http://dx.doi.org/10.3390/ijerph14121600. Acesso: 10/01/2019.

Leite, M. E., Silva, L. A. P., Leite, M. R.; Fonseca, G. S., 2018. Geotecnologias aplicadas a estimativa da temperatura de superfície em diferentes usos e ocupações do solo na Área de Proteção Ambiental do Rio Pandeiros - Minas Gerais. Caderno de Geografia 28, 490-509. Doi: http://10.5752/p.2318-2962.2018v28n53p490.

Nóbrega, R. S.; Santos, P. F. C.; Moreira, E. B. M., 2016. Morfologia urbana e ilhas de calor na cidade do Recife-PE: Distribuição Espacial e intensidade. Revista de Geografia (Recife) 33, 319-333.

Oke, T. R., 1987. Boundary Layer Climates. $2^{\mathrm{a}}$ ed. Routledge: London.

Porangaba, G. F. O; Teixeira, D.C.F.; Amorim, M. C. C. T., 2017. Procedimentos metodológicos para análise das ilhas de calor em cidades de pequeno e médio porte. Revista Brasileira de Climatologia [online] 21. Disponível: http://dx.doi.org/105380/abclima.v21i0.48832. Acesso: 12/08/2020.

R Development Core Team, 2016. R: A language and environment for statistical computing. R Foundation for Statistical Computing, Vienna.

Roth, M., 2007. Review of urban climate research in (sub) tropical regions. International Journal of Climatology 27, 1859-1873. Doi: http://dx.doi. org/10.1002/joc.1591

Sanches, F. O.; Fernandes, E.; Ferreira, R.V.; Firmino, G. V.; Alves, M. O., 2018. Contribuição ao estudo do clima urbano em Uberaba (MG), Revista Brasileira de Climatologia [online] 33. Disponível: http://dx.doi.org/10.5380/abclima.v1i0.60447. Acesso: 12/08/2020.
Santiago, D. B.; Gomes, H. B., 2016. Estudo de ilhas de calor no município de Maceió/AL usando dados orbitais do Landsat 5. Revista Brasileira de Geografia Física 9, 793-803.

Santos, K. P. C.; Cunha, A. C.; Souza, E. B.; Costa, A. C. L. 2012. Índices de Tendências Climáticas Associadas à "ilha de calor" em Macapá-AP. Revista Brasileira de Ciências Ambientais 23, 1-16.

Silva, A. P. N., 2016. Ilha de calor urbana: diagnóstico e impactos no microclima da região metropolitana de Macapá- AP. Tese (Doutorado). Campina Grande, UFCG.

Silva Junior, J. A., 2012. Avaliação de parâmetros micrometeorológicos, do conforto e da percepção térmica na área urbana da cidade de Belém-PA. Tese (Doutorado). Belém, UFPA.

Silva Junior, J. A.; Costa, A. C. L.; Pezzuti, J. C. B.; Costa, R. F.; Souza, E. B., 2012a. Relações entre as percepções térmicas e índices de conforto térmico dos habitantes de uma cidade tropical na Amazônia Oriental. Brazilian Geographical Journal 3, 395-407.

Silva Junior, J. De A.; Costa, A. C. L.; Pezzuti, J. C. B.; Costa, R. F.; Galbraith, D., 2012 b. Análise da Distribuição Espacial do Conforto Térmico na Cidade de Belém, PA no Período Menos Chuvoso. Revista Brasileira de Geografia Física 2, 218-232.

Silva Junior, J. A.; Costa, A. C. L.; Pezzuti, J. C. B.; Costa, R. F.; Rodrigues, H. J. B., 2013 a. Sazonalidade de elementos meteorológicos da área urbana e periférica na cidade de Belém, PA. Brazilian Geographical Journal 4, 650-662.

Silveira, I. M. M; Carvalho, R. G., 2016. Microclima e conforto térmico na área da Mata da Bica, no munícípio de Portalegre-RN. Revista Brasileira de Geografia Física 9, 062078.

Souza, D. O.; Alvalá, R. C. S., 2014. Observational evidence of the urban heat island of Manaus city, Brazil. Meteorological Applications [online] 21. Disponivel: http://dx.doi. org/10.1002/met.1340. Acesso: 07/09/2019.

Terra De Oliveira, M.; Ganem, K. A.; Batista, G. M. De M., 2017. Análise sazonal da relação entre sequestro de carbono e ilhas de calor urbanas nas metrópoles de São Paulo, Rio de Janeiro, Belo Horizonte e Brasília. Revista Brasileira de Cartografia 69, 807-825.

Torres, A. M, El-Robrini, M., Costa, W.J.P., 2018. Panorama da erosão costeira - Amapá, in: Muehe, D. (org.), Panorama da Erosão Costeira no Brasil. Ministério do Meio Ambiente (MMA), Brasília, pp. 19-63. 
Revista Brasileira de Geografia Física v.13, n.07 (2020) 3254-3274.

WMO. World Meteorological Organization, 2012. Guide to meteorological instruments and methods of observation. Geneva.

Zhang, X.; Steeneveld. G.; Zhou, D.; Duan, C.; Holtslag, A. A. M., 2019. A diagnostic equation for the maximum urban heat island effect of a typical Chinese city: A case study for Xi'na. Building and environment 158, 39-50. Doi: http://dx.doi.org/10.1016/j.buildenv.2019.05.0 04.

Zhou, B.; Rybski, D.; Kropp, J. P., 2017. The Role of city size and urban form in the surface urban heat island. Scientific Reports [online], 7. Disponivel: http://dx.doi. org/10.1038/s41598017-04242-2. Acesso: 23/01/2019.

Zhu, R., Wong, M. S.; Guilbert, E., Chan, P. W., 2017. Understanding heat patterns produced by vehicular flows in urban areas. Scientific Reports [online] 7. Disponível: http://dx.doi. org/10.1038/s41598-017-15869-6. Acesso: 23/01/2019. 